Soto, M.; Giraldo, J.; Mejía, J. (2018). Características de la información contenida en los reportes integrados: una visión para el mercado integrado de América Latina (MILA). Contaduría Universidad de Antioquia, 73, 163-198. Doi: https://doi.org/10.17533/udea.rc.n73a07

\title{
Características de la información contenida en los reportes integrados: una visión para el mercado integrado de América Latina (MILA)
}

John Alexander Giraldo López

john.giraldol@udea.edu.co

Holcrest S.A.S

Mateo Soto Sossa

smateo.soto@gmail.com

Deloitte \& Touche

Juan Andrés Mejía Delgado juan.mejiad@udea.edu.co

Hospital Pablo Tobón Uribe 
Características de la información contenida en los reportes integrados: una visión para el mercado integrado de América Latina (MILA)

Resumen: Los reportes integrados han nacido como una alternativa para que las empresas muestren cómo generan valor a los accionistas y el impacto que tienen sus operaciones en los ámbitos económico, social y ambiental. En éste trabajo se investigaron las características que presentan los reportes integrados del año 2014 de las empresas que conforman el mercado integrado latinoamericano (MILA). Para cumplir con el objetivo de la investigación se tomaron 24 empresas del Mercado integrado latinoamericano MILA; un grupo de 6 empresas por cada país seleccionadas intencionalmente, y se analizaron variables como la presentación, el gobierno corporativo y los componentes económico, social y ambiental. Se concluye que los reportes emitidos por las empresas del MILA en el año 2014 presentan características que satisfacen de manera general los estándares establecidos en las guías emitidas para la presentación y preparación de los mismos.

Palabras clave: Global Reporting Initiative (GRI), Mercado Integrado Latinoamericano (MILA), Generación de valor, reporte integrado y revelación

Characteristics of the information contained in integrated reports: a vision for the Latin American Integrated Market (MILA)

Abstract: Integrated reports are born as an alternative for companies to show how they generate value for shareholders and the impact of their operations on the economic, social and environmental areas. This work investigated the characteristics of the integrated reports for 2004 of the companies that make up the Latin American Integrated Market (MILA). To achieve the aim of this research, 24 companies were taken from the MILA: a group of 6 intentionally selected companies for each country; and variables such as presentation, corporate governance and economic, social and environmental components, were analyzed. It is concluded that the reports released by the MILA companies in the year 2014 present characteristics that generally satisfy the standards established in the guidelines issued for their presentation and preparation.

Keywords: Global Reporting Initiative (GRI), Latin American Integrated Market (MILA), value generation, integrated report and disclosure.

Caractéristiques de l'information contenue dans les rapports intégrés : une vision pour le Marché Intégré Latino-américain (MILA)

Résumé: Les rapports intégrés ont apparu comme une alternative pour les entreprises pour démontrent comment elles créent de la valeur aux actionnaires et l'impact de leurs opérations sur les domaines économique, social et environnemental. Cet article montre les recherches faites sur les caractéristiques des rapports intégrés de l'année 2014 des entreprises conformant le Marché Intégré Latino-américain (MILA). Pour atteindre le but de cette recherche, nous avons pris en compte 24 entreprises du MILA, un groupe de 6 entreprises choisies exprès pour chaque pays. Ensuite, nous avons analysé des variables telles que la présentation, la gouvernance corporative et les composants économique, social et environnemental. Nous avons pu conclure que les rapports émis par les entreprises du MILA en 2014 présentent des caractéristiques répondant aux standards établis dans les guides pour la présentation et la préparation de ceux-ci.

Mots-clés : Global Reporting Initiative (GRI), Marché Intégré Latino-américain (MILA), création de valeur, rapport intégré et divulgation.

Características da iformação contida nos relatórios integrados: uma visão para o Mercado Integrado de América Latina (MILA)

Resumo: Os relatórios Integrados nasceram como uma alternativa para que as empresas mostrem como gerar valor aos acionistas e o impacto que têm suas operações nos âmbitos económico, social e ambiental. Neste trabalho, foram pesquisadas as características que apresentam os relatórios integrados do ano 2014 das empresas que conformam o Mercado Integrado da América Latina (MILA). Para alcançar o objetivo da pesquisa tomaram-se 24 empresas do Mercado Integrado da América Latina (MILA); um grupo de seis empresas por cada país escolhidas intencionalmente, $e$ analisaram-se variáveis como a apresentação, o governo corporativo e os componentes econômico, social e ambiental. Conclui-se que os relatórios emitidos pelas empresas do MILA no ano 2014 apresentam características que satisfazem de forma geral os padrões estabelecidos nas guias emitidas para a apresentação dos mesmos.

Palavras chave: Global Reporting Initiative (GRI), Mercado Integrado da América Latina (MILA), Geração de Valor, Relatório Integrado e revelação. 


\title{
Características de la información contenida en los reportes integrados: una visión para el mercado integrado de América Latina (MILA)
}

\author{
John Alexander Giraldo López, Mateo Soto Sossa y Juan Andrés Mejía Delgado \\ Doi: https://doi.org/10.17533/udea.rc.n73a07
}

Primera versión recibida en agosto 2018 - Versión final aceptada en octubre 2018

\section{Introducción}

$\mathrm{C}^{\mathrm{l}}$ presente trabajo aborda las características de reporte de información que Cresentan las organizaciones en los tiempos contemporáneos, ya que es claro que en la época actual predomina la idea de mercados globales y de lenguaje universal, en donde la comunidad empresarial enfrenta el reto de hallar e implementar estrategias para mantener altos niveles de competitividad y a su vez para dar a conocer de manera asertiva los logros de la gestión realizada.

El mundo empresarial se encuentra cada vez más pendiente de las dinámicas que va tomando el mercado para evitar que otras organizaciones tomen ventajas competitivas que afecten el funcionamiento de sus negocios, además de esto, han entendido que ahora ya no es suficiente comunicar únicamente la información financiera que se deriva de un periodo determinado, sino que los agentes de interés exigen una visión más amplia de la organización (CorreaGarcía et al., 2016). Es en este sentido en donde los reportes corporativos aparecen como un aliado importante al abordar información de carácter financiero y no financiero, además de proporcionar una visión más amplia de las acciones realizadas por los entes económicos en una época en donde la transparencia institucional se ha convertido en un factor de referencia, ya que "una de las formas de evaluar la transparencia informativa de las empresas de un determinado sector o país es su medición a través de los denominados Índices de revelación de información" (García, 2015, P. 65), generando un alto nivel de confiabilidad en criterios de decisión por parte de agentes de interés.

Con el objetivo de brindar una noción acerca de las características de la información que presentan las empresas en un entorno latinoamericano, en 
Soto, M.; Giraldo, J.; Mejía, J. Características de la información contenida en los reportes integrados...

éste trabajo se tomó como referencia una muestra intencionada del Mercado Integrado Latinoamericano (MILA), con las cuales se busca caracterizar la información emitida por sus empresas de acuerdo a criterios establecidos por guías como GRI, IR y algunos desarrollos teóricos. Para llevar esto a cabo este trabajo se dio a conocer una noción general de lo que son los reportes integrados, del rol que tienen estos en la explicación del proceso de generación de valor y de la manera en que este concepto ha sido desarrollado y ha evolucionado en el transcurso del tiempo. Posteriormente se realizó un análisis de resultados con base a la muestra y metodología establecida, que permitieron generar la conclusión de que los reportes emitidos por las empresas seleccionadas del MILA presentan características que satisfacen de manera general los estándares establecidos en las guías emitidas para la presentación y preparación de los mismos.

\section{Generalidades de los reportes integrados}

Las organizaciones han comprendido cada vez más que "la necesidad de preservar los recursos naturales para las futuras generaciones es un tema relevante a nivel global" (Marianne, L. 2015, P. 3. Traducción de los autores), pues la escasez de recursos naturales generada en gran parte por los impactos negativos que ocasionan las operaciones de las compañías ha despertado en las comunidades mundiales un interés por crear campañas y leyes que ayuden a preservar la naturaleza.

Hace algunas décadas la tendencia era presentar información netamente financiera e histórica, pero los diferentes sucesos en la economía, entre ellos las crisis financieras internacionales, han generado un cambio en la perspectiva empresarial, como lo afirma Chersan Ionela Corina:

Las recientes crisis económicas mundiales se han convertido en un llamado para despertar de un letargo, pues ha quedado claro que a las empresas se les dificulta desarrollar sus actividades bajo las condiciones de un mundo que vive al borde del colapso. (2015, P. 92. Traducción de los autores)

Esta situación ha impulsado la presentación de información enfocada en establecer la relación de la empresa con los actores externos que afectan sus operaciones; ya que una empresa no crea o destruye valor por sí sola, sino que en ella influyen factores tales como la economía, la sociedad y el medio ambiente (Correa y Hernández, 2017).

Actualmente existen varias organizaciones que promueven la elaboración de reportes integrados, algunas de estas son:

- Global Reporting Initiative: Con su última guía emitida, la G4 es una de las guías más usadas a nivel mundial.

- International Integrated Reporting Council: Presenta el Marco IR como una guía para la elaboración de reportes integrados. 
- Organización Internacional de Normalización: Emite la guía ISO 26000 como una ayuda para la implementación de prácticas de responsabilidad social, tanto en entes gubernamentales como privados. Esta norma trabaja sobre 7 temas fundamentales, los cuales son:

- Derechos humanos.

- Prácticas laborales.

- Medio ambiente.

- Practicas justas de operación.

- Asuntos de consumidores.

- Participación activa y desarrollo de la comunidad.

- Sustainability Accounting Standards Board: Emite la "SASB implementation guide for companies" como una guía para compañías que busquen implementar "sustainability accounting standards" entres sus operaciones normales.

Para la elaboración de este artículo se trabajó con base al contenido de las guías que presentan el GRI y el IIRC ya que estas son las de mayor utilización a nivel mundial y son las que recogen la mayor cantidad de elementos compatibles con el objetivo de un pensamiento integrado (WBCSD, 2017).

A continuación, se presentan los aspectos más importantes de las guías emitidas por el GRI y el IIRC.

Tabla 1. Comparación GRI vs IR

\begin{tabular}{|c|c|c|}
\hline Tema & Reporting Initiative - G4Global & International Integrated Reporting Council - IR \\
\hline$\frac{\dot{0}}{\stackrel{0}{0}}$ & $\begin{array}{l}\text { "Las memorias de sostenibilidad analizan } \\
\text { la relevancia de la sostenibilidad para una } \\
\text { organización y abordan las prioridades y } \\
\text { los asuntos clave en ese ámbito" (G4, 2013, } \\
\text { P. 85) }\end{array}$ & $\begin{array}{l}\text { "Un informe integrado es una } \\
\text { de cómo la estrategia de uI } \\
\text { gobierno corporativo, desemp } \\
\text { en el contexto de su entorno e } \\
\text { a crear valor en el corto, mec } \\
\text { (IIRC, 2013, P. 8) }\end{array}$ \\
\hline 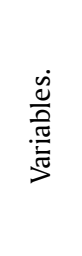 & $\begin{array}{l}\text { Establece principios que deben ser } \\
\text { tomados como base para la elaboración } \\
\text { de la memoria, estos son: participación } \\
\text { de los grupos de interés, contexto de } \\
\text { sostenibilidad, materialidad, exhaustividad, } \\
\text { equilibrio, comparabilidad, precisión, } \\
\text { puntualidad, claridad y fiabilidad. }\end{array}$ & $\begin{array}{l}\text { tablece directrices que guían la preparación del } \\
\text { forme integrado, estas son: enfoque estratégico y } \\
\text { ientación futura, conectividad de la información, } \\
\text { laciones con los grupos de interés, materialidad, } \\
\text { ncisión, fiabilidad y exhaustividad, y consistencia } \\
\text { comparabilidad. }\end{array}$ \\
\hline 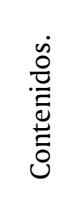 & $\begin{array}{l}\text { Los contenidos básicos que debe tener la } \\
\text { memoria de sostenibilidad son: estrategia y } \\
\text { análisis, perfil de la organización, aspectos } \\
\text { materiales y cobertura, participación de los } \\
\text { grupos de interés, perfil de la memoria, } \\
\text { gobierno y ética e integridad. }\end{array}$ & $\begin{array}{l}\text { El informe integrado debe tratar lo siguiente: } \\
\text { descripción de la organización y del entorno } \\
\text { externo, gobierno corporativo, modelo de negocio, } \\
\text { riesgos y oportunidades, estrategia y asignación de } \\
\text { recursos, desempeño y perspectiva. }\end{array}$ \\
\hline
\end{tabular}


Soto, M.; Giraldo, J.; Mejía, J. Características de la información contenida en los reportes integrados...

\begin{tabular}{|c|c|c|}
\hline Tema & Reporting Initiative - G4Global & International Integrated Reporting Council - IR \\
\hline 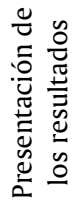 & $\begin{array}{l}\text { La información se presenta con base en } \\
\text { indicadores que ayudan a presentar el } \\
\text { desempeño de la empresa. }\end{array}$ & $\begin{array}{l}\text { No es necesario la presentación de indicadores } \\
\text { o métodos de medición pero incluye los } \\
\text { requerimientos que deben ser aplicados para que } \\
\text { el informe integrado este de conformidad con el } \\
\text { marco. }\end{array}$ \\
\hline 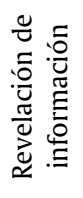 & $\begin{array}{l}\text { La revelación de la información se divide } \\
\text { en indicadores de tipo: económico, social } \\
\text { y ambiental. }\end{array}$ & $\begin{array}{l}\text { La revelación de información se divide en seis } \\
\text { categorías de capitales: financiero, industrial, } \\
\text { humano, social y relacional, intelectual y natural. }\end{array}$ \\
\hline 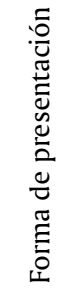 & $\begin{array}{l}\text { Tiene dos opciones de presentación, la } \\
\text { esencial y la exhaustiva, la esencial consta } \\
\text { de presentación de información económica, } \\
\text { social y ambiental y la exhaustiva es la } \\
\text { esencial y le incorpora nuevos contenidos } \\
\text { relativos a la estrategia, el análisis, el } \\
\text { gobierno, la ética y la integridad de la } \\
\text { organización. }\end{array}$ & $\begin{array}{l}\text { Si se pretende realizar un reporte integrado con } \\
\text { base en el marco del IR se debe cumplir con todos } \\
\text { los requisitos exigidos por este y los que no sea } \\
\text { posible cumplir indicar el tipo de información que } \\
\text { se ha omitido, las razones por la cuales se omitió y } \\
\text { si no es posible acceder a la información indicar las } \\
\text { medidas tomadas para acceder a esta. }\end{array}$ \\
\hline
\end{tabular}

Fuente: Elaboración propia con base en Global Reporting Initiative. (2013). Guía para la elaboración de memorias de sostenibilidad G4. International Integrated Reporting Council. (2013). El marco Internacional IR.

Se evidencia de manera general el interés de ambas guías para que las compañías muestren los impactos negativos y positivos como se afirma en el Manual IR "Un informe integrado debe incluir todos los asuntos materiales, tanto positivos como negativos" (2013. P. 22) que tienen sobre tres aspectos; el económico, el ambiental y el social como una fuente informativa que evidencie el compromiso de las organizaciones por tener una perspectiva más incluyente ante la sociedad.

\section{Reportes integrados y su rol en la generación de Valor}

En los objetivos que se proponen las empresas actualmente sobresalen la competencia y la innovación, obtener altos niveles de diferenciación y reconocimiento en el medio en el cual hacen presencia. Para esto se buscan estrategias y herramientas que orienten y conlleven a mejores prácticas que contribuyan al alcance de las metas propuestas. Es así como en esa búsqueda de mejoramiento continuo aparecen nuevas tendencias, ideas y teorías de aplicación. En esta línea las organizaciones alienan sus esfuerzos en pro de la generación de valor, que se convierte en uno de los pilares sobre los cuales las empresas trabajan para potenciar su desempeño y su buena imagen ante la sociedad. 
Ante estas nuevas tendencias en la información "las empresas que tienen un compromiso ético con sus grupos de interés (stakeholders) en los informes anuales se comportan financieramente mejor". (Mascareñas, 1999, P. 17) convirtiendo la información presentada por las organizaciones en un aspecto relevante.

\section{III.1 Generación de valor: un objetivo sobresaliente de los reportes integrados.}

La generación de valor es un concepto que ha venido siendo trabajado desde hace algún tiempo como afirma García, "En los últimos años se ha visto cómo las empresas han acogido el término valor agregado como uno más de su lenguaje cotidiano. Valor agregado para los clientes, cadena de valor agregado, decisiones que agreguen valor, etc.," (2003, P. 1), esta tendencia se ha ido generalizando debido a las exigencias y la nueva dinámica del mercado en donde cada vez es más evidente que "El valor de las empresas en el mercado depende de las percepciones de los inversores y de la habilidad de los directivos de anticiparse y responder a los futuros cambios del entorno empresarial." (Healy y Palepu, 2001 citado en Gil, 2012) y cada vez es más frecuente el enfoque que las organizaciones realizan en pro de alcanzar unos altos niveles de desempeño y de mejora en la gestión realizada.

Se debe tener claro que, para lograr una adecuada gestión del valor, las organizaciones deben realizar una serie de procesos que integren su funcionamiento. Tal y como se menciona a continuación:

Primero, desarrollar estrategias para maximizar el valor; segundo, traducir la estrategia en metas de corto y largo plazo que se enfoquen en los principales inductores de valor; tercero, desarrollar planes de acción y presupuestos enfocados al cumplimiento de las metas de corto y mediano plazo; y cuarto, introducir sistemas de medición de resultados y esquemas de compensación con el fin de monitorear e incentivar a los empleados para que cumplan las metas establecidas. (Dinero, 1998)

Con un adecuado entendimiento y la unificación de los intereses de la sociedad se puede lograr el cumplimiento del objetivo básico financiero que no es más que "la maximización del patrimonio de los propietarios" (García, 2003, P. 3), además de contribuir a la mitigación de las preocupaciones generadas por "el flujo mundial de capitales, los retos de la globalización, las privatizaciones y la necesidad de mejores medidas para evaluar el desempeño" (García, 2003, P.5). De esta manera se contemplan perspectivas enfocadas en la innovación y el aprendizaje, los procesos internos, el cliente, el ámbito financiero y una relación cercana con el desarrollo sostenible.

La gestión orientada al valor también se ha venido convirtiendo en una oportunidad para que las organizaciones puedan potenciar su desempeño y para demostrar ante la sociedad la capacidad de adaptación y de respuesta, que se tiene ante el dinamismo del mercado actual, con una perspectiva integral. 
Soto, M.; Giraldo, J.; Mejía, J. Características de la información contenida en los reportes integrados...

\section{III.2 Revelación de Información, información integrada y generación de valor.}

En los últimos tiempos, en las organizaciones se ha procurado por una tendencia cada vez más encaminada hacia la utilización de información de tipo financiero y no financiero, esta orientación ha sido motivada por las exigencias que realiza el mercado, los clientes y los inversionistas, quienes día a día pretenden conocer un poco más acerca de las entidades en las que concentran sus expectativas y sus intereses.

La información integrada toma relevancia en la generación de valor en la medida en que esta sirve como enlace y como ruta de seguimiento a los procesos desarrollados, ya sean directivos, financieros y administrativos o de gestión que se hayan venido ejecutando en la compañía para orientar los objetivos en pro del alcance del bienestar general y del cumplimiento de metas a largo y a corto plazo tal y como se expresa en la traducción realizada por AECA a lo expresado por el Integrated Reporting:

La Información Integrada reúne la información relevante acerca de la estrategia de una organización, la gestión, los resultados y las perspectivas de una manera que refleje el contexto social, comercial y medioambiental en el que opera. Proporciona una representación clara y concisa de cómo una organización evidencia su administración y cómo se crea y sostiene el valor. (2011. P. 4)

El objetivo principal se enfoca en la generación de valor y para comprender esta situación es importante aclarar que compañía no sólo crea valor aumentando su liquidez y siendo más productiva, sino que también crea valor cuando tiene impactos positivos en los factores externos como el económico, social y ambiental, pues según Monterio (2013) una empresa puede crear valor aumentando su capital, ya sea financiero, intelectual o ambiental.

La información integrada, busca garantizar que la evolución de la información sea constante y por tanto exista un norte que incentive a las organizaciones a mejorar y a estar en la búsqueda de la implementación de nuevas propuestas para tener cada día una mejor relación entre su objeto social, la comunidad y el entorno.

La relación de la empresa con el entorno, el objeto social y la generación de valor es un tema que ha venido siendo trabajado desde hace algún tiempo en donde se ha abordado información para diferentes tipos de usuarios como lo son: empleados, clientes, proveedores, competidores, comunidad local, medio ambiente y sociedad en general. (Lizcano, 2006, citado en Marín, Maldonado y Domínguez ,2012) brindando así una perspectiva más integral de la información.

Existen factores que tienen una incidencia directa en la revelación de información por parte de una empresa y que en última instancia contribuyen a la generación de valor agregado. Un ejemplo de esto es tratado por \{Formatting 
Citation\} al relacionar la revelación de información (apoyado en la teoría de las señales) con el coste beneficio para la empresa, en la cual la revelación de información permite reducir los costes de financiación y además corregir asimetrías en la información que se encuentra en el mercado, lo cual se ve repercutido en la empresa al evitar la incertidumbre del mismo.

Otro caso se presenta en la teoría de la agencia donde se considera la información como un factor esencial en la toma de decisiones y en el proceso de control de los directivos (Jensen y Meckling, 1976 Citado en Rodríguez y otros, 2010). También se presenta un aporte desde la teoría de los costes políticos expuesta por Jensen y Meckling (1976, citado en Rodríguez y otros, 2010) en la cual señalan que la revelación de información permite reducir costos relativos a temas impositivos como pueden ser tasas de intereses, subvenciones, entre otros.

En última instancia Babío et al. (2003) relacionan los costos-beneficios con la difusión de la información por parte de la empresa a todos los usuarios interesados.

En consecuencia, la publicación de información destinada a satisfacer las necesidades de los usuarios, o a dar respuesta a diferentes presiones, se verá condicionada por el resultado de algún tipo de análisis coste-beneficio desarrollado por la empresa y del que se derivará una respuesta afirmativa cuando el efecto neto de la difusión de información sea positivo para la entidad. (P. 3)

Según esto, la revelación de información se encuentra directamente relacionada con el bienestar que genera la empresa, el cual se ve reflejado en la misma al crear valor puesto que así genera una buena imagen ante los agentes de interés (Babío et al. 2003).

Frente a la revelación de información en relación con algunos componentes de la información integrada, Moneda y Llena (1996) realizan una mención de la revelación de información por parte de la empresa refiriéndose especialmente al componente social y ambiental:

Estas nuevas características que se introducen en el concepto de empresa vienen a incorporar a su relevancia económica una trascendencia social, que ya está latente en la sensibilidad de la sociedad; así se demuestra en el comportamiento de las fuerzas sociales ante determinados hechos: ubicación de una gran empresa en una zona con elevados índices de desempleo, emisión de residuos tóxicos, patrocinio de actividades culturales y benéficas, etc. (P. 5)

La información de tipo social dentro de la revelación de información por parte de las organizaciones tiene un fuerte impacto al momento de crear valor. Al referirse a la integración de esta información Patten, 1992; López y Rodríguez, 2004; Ayala, 2007; Garza, 2008 (citados en Marín y otros, 2012) mencionan que: 
Soto, M.; Giraldo, J.; Mejía, J. Características de la información contenida en los reportes integrados...

Como parte de esta integración se incluye la problemática de la transparencia informativa. Así, la rendición de cuentas, como mecanismo de divulgación, busca, por un lado, mantener informados a los stakeholders sobre las actuaciones responsables de la empresa y, por otro, legitimar a la empresa frente al mercado. (P. 126)

En cuanto a información medioambiental Archel y Lizarraga (2001) señalan que existe un contrato entre la sociedad y la empresa, el cual es dinámico y puede ser modificado o revocado en caso de que alguna de las partes no cumpla con las expectativas establecidas; para esto, la empresa debe presentar información que vaya encaminada a la relación que tiene con la sociedad, de igual forma esta debe revelar información tanto positiva como negativa puesto que la ausencia de revelación de información puede entenderse como malas noticias o inexactitudes en la misma. Babío et al. (2003)

Es oportuno hacer énfasis en que las organizaciones han generado valor en la medida en que han entendido que el mercado actual cada vez busca mayores niveles de transparencia, los cuales pueden ser logrados con información más completa e integral que demuestre "que son socialmente responsables por sus actuaciones en el mercado". (Prestton Y Brown, 1981 citados en Archel y Lizarraga, 2001) y que están dispuestas a realizar esfuerzos para contribuir con su entorno.

\section{Un breve recorrido histórico y de antecedentes de la información integrada.}

Desde hace algunas décadas la economía mundial ha experimentado un crecimiento significativo, lo que ha generado problemas como el deterioro del medio ambiente, aumento de desequilibrios sociales y mala distribución de la riqueza (Iñaki Gili y Salas, 2005). Esto ha impedido que el desarrollo logre ser sostenible en el tiempo y ha incentivado a las empresas a buscar prácticas que sean más amigables con el medio ambiente y procurar que los efectos adversos creados a la sociedad se minimicen.

A principios de la década de los 90 varias organizaciones mundiales empezaron a promover un conjunto de normas que ayudaran a establecer procesos en las empresas que fueran más amigables con el medio ambiente y lograr que estas a la vez fueran más eficientes, esto con el objetivo de "hacer más con menos" (Iñaki Gili y Salas, 2005). Las crisis económicas que se han presentado también han sido un factor que ha puesto en evidencia la necesidad de que las empresas presenten información adicional, que trascienda la financiera, para lograr una mejor comprensión de las operaciones de la compañía y darles una mayor interpretación a las cifras presentadas.

En el año 1997 se crea el Global Reporting Initiative (GRI) con el objetivo de desarrollar una guía para la elaboración de un informe de sostenibilidad que abarcara no sólo temas ambientales sino también de tipo económico y social 
por medio del desarrollo de indicadores que mostraran la eficacia y eficiencia de las operaciones de la empresa, el uso de recursos naturales, el trato a los empleados y el respeto a los derechos humanos.

En apoyo a esto se menciona la creación del Dow Jones Sustainability World Indexes en el año 1999, el cual ayudó a promover la revelación de informes de sostenibilidad e impulsó la inclusión del pensamiento integrado en las compañías, pues en este índice se encontraban las organizaciones líderes en sostenibilidad, evidenciando la preocupación generalizada de realizar prácticas amigables con el entorno y proporcionar información más completa.

A continuación, se presenta una relación temporal de las guías emitidas por el GRI:

Ilustración 1. Relación temporal emisión de guías GRI

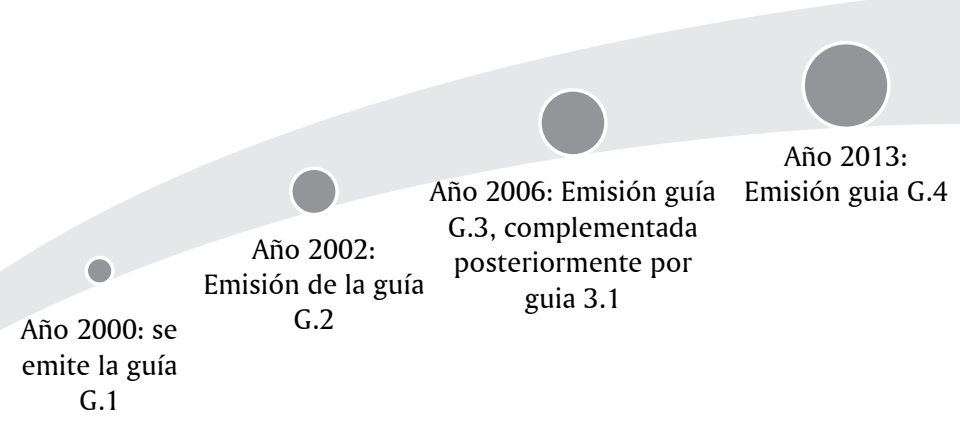

Fuente: Global Reporting Initiative (2015)

La guía G4 se definió como un gran paso hacia la presentación de reportes de sostenibilidad mejor estructurados y con una mayor posibilidad de lograr una mirada amplia de las empresas e integrar diferentes tipos de información que sea útil para los usuarios. Esta guía presenta indicadores que miden mejor la eficiencia y eficacia de las operaciones de la compañía, su costo es menor y por lo tanto puede ampliar el rango de aplicación y de cobertura para facilitar la preparación a empresas en desarrollo.

El 2009 fue un año de grandes cambios para los informes de sostenibilidad ya que se crea el International Integrated Reporting Council (IIRC) definido según el IIRC como una organización sin ánimo de lucro que se crea por medio de una coalición global interdisciplinaria con el fin de promover la presentación de información que ayude en la generación de valor, integrando datos financieros, información relacionada con la administración de la compañía y sostenibilidad de la misma (International Integrated Reporting Council, 
Soto, M.; Giraldo, J.; Mejía, J. Características de la información contenida en los reportes integrados...

2013). Este marco promueve el mejoramiento de la calidad de la información para tener una adecuada distribución del capital y promover que se brinde información acerca de los factores materiales que afecten la habilidad del negocio para generar valor.

Para el año 2012 Latinoamérica se convirtió en una de las regiones que más presentó certificaciones del GRI donde se destacan compañías de Brasil, México y Colombia, entre otros países. La cantidad de certificaciones obtenidas doblaron la cantidad que se presentaron en África y triplicaba la cantidad de Oceanía, esta situación prevé que para los próximos años se pronostique una alta saturación de certificaciones en el mercado latinoamericano (Almeida, María del Mar. Marimon, Frederich. Llach, Josep. 2015)

En la actualidad existe una tendencia a la mejora y la transparencia de la información emitida por las organizaciones, es por esto que se hace importante asociar este tipo de prácticas a un mercado en específico, que brinde un acercamiento del estado de aceptación que estas prácticas han tenido y a la vez dar una noción de la relevancia que estos pueden tener en la imagen corporativa de las organizaciones que lo aceptan y lo adoptan.

\section{Desarrollo Metodológico}

Para la realización de este trabajo se optó por tomar el MILA como espacio muestral de referencia reconociendo que, para el año 2015, éste se ha fortalecido y ha venido en constante crecimiento desde la fecha de su creación en el 2011. A partir de esto, se procedió a realizar una revisión documental de los Reportes Integrados, su concepto y sus características, así como de los organismos que los integran y que disponen tanto de estructuras como de lineamientos de preparación y presentación, y de temas relacionados con la generación de valor en las organizaciones.

El mercado integrado latinoamericano "MILA" nace en mayo de 2011, conformado por los Países de Chile, Colombia y Perú en busca de diversificar $\mathrm{y}$ aumentar sus inversiones. Al nacer este mercado las expectativas han sido notables como lo menciona Llorente y Cuenca (2011), en su informe Transacciones en Latinoamérica:

El MILA es hoy una operación que sitúa a Latinoamérica a la altura de la corriente global que tiende a la consolidación de los mercados a través de la integración de las distintas plazas como es el caso de Nueva York y Frankfurt o la adquisición de la Bolsa de Toronto por parte del London Stock Exchange. Todo ello bajo un panorama internacional alentado por la oleada de oportunidad en dichos movimientos. (P. 3)

También como lo menciona Echavarría (2011) citado en Arango y Upegui (2012)

Esta integración genera un crecimiento económico favorable para la región, un incremento de inversión extranjera directa y liquidez, fomenta la participación en 
los mercados y aumenta la gama de productos ofrecidos generando más alternativas de inversión. Pues se genera la integración de tres bolsas de diferentes países que se complementan estructuralmente: Chile es un mercado diversificado pero fuerte en energía, títulos financieros y de consumo, Perú es un mercado concentrado un $50 \%$ en minería y Colombia es un mercado petrolero. (P. 22)

A finales del año 2014 ingresa México al MILA con lo cual este mercado se convierte en un referente para la región, tal y como lo menciona el Banco Interamericano de Desarrollo (2015), el MILA pasa a ser el primer mercado de América Latina por capitalización bursátil con un total de US\$ 1,1 mil millones y un número de empresas de 986, las cuales sólo son superadas por Bovespa (Bolsa de Valores de São Paulo).

Algo que cabe resaltar de la integración de las 4 bolsas de valores es que se encuentran relacionadas con la Alianza del Pacifico. Esta Alianza está conformada por los países de Colombia, Chile, México y Perú el cual es un mecanismo de articulación de los 4 países para mejorar las negociaciones como lo menciona Hernández y Muñoz (2015, p 103.) "la AP (Alianza del pacifico) recoge así un grupo de países que coinciden en el manejo de la política y la economía, (...), y caracterizados por su compromiso con el libre comercio como vehículo para el desarrollo de sus sociedades". De esta unión se puede considerar que nace la iniciativa del MILA en donde el Ministerio de Comercio, Industria y Turismo de Colombia (s.f.) menciona:

Uno de los temas de mayor impacto que plantea la Alianza del Pacífico es la libre movilidad de capitales y un primer paso de este propósito fue la creación del Mercado Integrado Latinoamericano (MILA) que busca fomentar el crecimiento de la actividad bursátil de los países integrantes.(parra. 53)

De acuerdo a esto, se puede considerar que el MILA tiene un fuerte apoyo al estar respaldado por una de las más grandes alianzas de América lo cual trae consigo más solidez en las relaciones de negocios entre los países y una gran expectativa hacia el futuro.

El MILA es uno de los acuerdos y uno de los avances más sobresalientes de la Alianza del Pacifico (Hernández y Muñoz, 2015, p. 103) y es importante resaltar que la integración del mercado bursátil entre economías de diferentes lugares de origen puede llegar a ser compleja, pues esta situación genera ciertas incompatibilidades como por ejemplo las diferencias entre las disposiciones normativas de cada país, tanto en términos fiscales como en términos bursátiles considerando las diferencias en tipos de moneda y tasa de cambio.

Con respecto a lo mencionado en el párrafo anterior, cada Estado cuenta con instituciones reguladoras y de depósito que buscan generar un ambiente apto para la negociación entre países. De acuerdo a esto es importante conocer cuáles son los encargados de administrar y afinar las negociaciones que se producen; como menciona Arango y Upegui (2012) 
Soto, M.; Giraldo, J.; Mejía, J. Características de la información contenida en los reportes integrados...

Es importante conocer los depósitos de valores de cada uno de los países y las entidades reguladoras de los mercados de valores. Pues los primeros son instituciones que se crearon con el fin de administrar la custodia los títulos bursátiles. Se encargan entonces de liquidar, transferir y custodiar los títulos de los inversionistas. Las entidades reguladoras se encargan de la supervisión, regulación y control del mercado de valores. (P. 31)

En el siguiente cuadro se presentan las instituciones de reguladores junto con la Bolsas de Valores y los Depósitos centrales de valores de cada uno de los países que conforman el MILA.

Tabla 2. Reguladores MILA por país

\begin{tabular}{|c|c|c|c|}
\hline & Reguladores & Bolsas & Depósitos \\
\hline Colombia & $\begin{array}{l}\text { Superintendencia Financiera } \\
\text { de Colombia } \\
\text { Superntendencia } \\
\text { fonancier } \\
\text { de colombia }\end{array}$ & Bolsa de Valores de Colombia & $\begin{array}{c}\text { Depósito Central de Valores } \\
\text { Deceval }\end{array}$ \\
\hline Perú & $\begin{array}{l}\text { Superintendencia del } \\
\text { Mercado de Valores }\end{array}$ & Bolsa de Valores de Lima & $\begin{array}{l}\text { Caja de Valores de Lima } \\
\text { CAVALI }\end{array}$ \\
\hline Chile & $\begin{array}{c}\text { Superintendencia de Valores } \\
\text { y Seguro }\end{array}$ & $\begin{array}{l}\text { Bolsa de Valores de Santiago } \\
\text { Bolsa Comercio }\end{array}$ & $\begin{array}{l}\text { Depósito Central de Valores } \\
\text { :OCV:- }\end{array}$ \\
\hline México & $\begin{array}{l}\text { Comisión Nacional Bancaria y } \\
\text { de Valores }\end{array}$ & Bolsa de Valores de México & $\begin{array}{l}\text { Depósito Central de Valores } \\
\text { Indeval }\end{array}$ \\
\hline
\end{tabular}

Fuente: Elaboración propia

En cuanto a la selección de la muestra, con el fin de cumplir con el objetivo de investigación y a la vez tener un mayor alcance en la misma, ésta se toma con referencia a diciembre 31 de 2014, fecha en la cual el país de México es un integrante más en el MILA. En adición a lo anterior, se decide optar por un muestreo de carácter no probabilístico; conformando una muestra intencionada de un número arbitrario de 24 empresas del total del MILA, Mercado en el cual se encontraban listadas 738 empresas (emisores) a 31 de diciembre de 2014.

Teniendo claro que uno de los objetivos de la investigación busca revelar como los reportes corporativos son presentados de acuerdo a su país de origen, se optó por elegir intencionalmente 6 empresas por cada país, generando así un muestreo equitativo y brindando mayor uniformidad en los criterios de análisis.

Con el fin de apoyar la muestra intencionada y darle solidez a la misma, en el siguiente cuadro se presenta la información porcentual de la capitalización bursátil de cada empresa elegida con respecto al monto total del capital bursátil de cada país a 31 de diciembre de 2014 . 
Tabla 3. Capitalización bursátil 2014

\begin{tabular}{|c|c|c|c|c|c|c|c|c|c|c|c|}
\hline \multicolumn{12}{|c|}{ CAPITALIZACIÓN BURSÁTIL A 31 de DICIEMBRE de 2014} \\
\hline \multicolumn{3}{|c|}{$\begin{array}{l}\text { CAPITAL BURSATIL MILA- COLOMBIA } \\
2014\end{array}$} & \multicolumn{3}{|c|}{ CAPITAL BURSATIL MILA- México 2014} & \multicolumn{3}{|c|}{$\begin{array}{c}\text { CAPITAL BURSATIL MILA- PERU } \\
2014\end{array}$} & \multicolumn{3}{|c|}{ CAPITAL BURSATIL MILA- CHILE 2014} \\
\hline$\$$ & & 153.079 .000 .000 & $\$$ & & 480.956 .989 .000 & $\$$ & & 120.763 .041 .940 & $\$$ & & $95.129 .705 .122,08$ \\
\hline Empresas & & $\begin{array}{l}\text { ap. Bursátil en } \\
(\$, \%)\end{array}$ & Empresas & & Bursátil en (\$, \%) & Empresas & & $\begin{array}{l}\text { aap. Bursátil en } \\
\text { (\$, \%) }\end{array}$ & Empresas & & $\begin{array}{l}\text { Cap. Bursátil en } \\
(\$, \%)\end{array}$ \\
\hline \multirow{2}{*}{ ECOPETROL } & $\$$ & 35.964.143.309 & AMERICA & $\$$ & 25.295 .800 .186 & SOUTHERN & $\$$ & 25.034 .069 .234 & S.A.C.I. Falabella y & $\$$ & 16.319 .016 .778 \\
\hline & & $23 \%$ & MOVIL, & & $5 \%$ & COPPER & & $21 \%$ & Filiales & & $8 \%$ \\
\hline \multirow{2}{*}{ GRUPOAVAL } & $\$$ & 12.154 .783 .805 & FOMENTO & $\$$ & 15.213 .838 .347 & CREDICORP & $\$$ & 15.138 .923 .647 & & $\$$ & 15.138 .923 .647 \\
\hline & & $8 \%$ & ECONÓMIC & & $3 \%$ & LTD & & $13 \%$ & 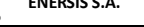 & & $8 \%$ \\
\hline \multirow{2}{*}{ BCOLOMBIA } & $\$$ & 10.948 .329 .403 & JPO TELEVIS & $\$$ & 13.229 .519 .701 & SOCIEDAD & $\$$ & 8.401 .344 .288 & EMPRESAS COPEC & $\$$ & 8.401 .344 .288 \\
\hline & & $7 \%$ & & & $3 \%$ & MINERA & & $7 \%$ & S.A. & & $4 \%$ \\
\hline \multirow{2}{*}{ GRUPOSURA } & $\$$ & 9.655 .896 .316 & GRUPO & $\$$ & 10.902 .790 .647 & BANCO DE & $\$$ & 8.392 .842 .426 & EMPRESA & $\$$ & 8.392 .842 .426 \\
\hline & & $6 \%$ & FINANCIER & & $2 \%$ & CREDITO & & $7 \%$ & NACIONAL DE & & $4 \%$ \\
\hline \multirow{2}{*}{ BOGOTÁ } & $\$$ & 9.208 .429 .220 & CEMEX, & $\$$ & 9.937 .159 .818 & BBVA & $\$$ & 5.052 .332 .134 & & $\$$ & 5.052 .332 .134 \\
\hline & & $6 \%$ & S.A.B. DE & & $2 \%$ & BANCO & & $4 \%$ & BAINCO DE CHILE & & $3 \%$ \\
\hline \multirow{2}{*}{ GRUPOARGOS } & $\$$ & 6.855 .303 .287 & GRUPO & $\$$ & 9.861 .500 .215 & INTERCORP & $\$$ & 3.438 .570 .266 & BANCO & $\$$ & 3.438 .570 .266 \\
\hline & & $4 \%$ & MÉXICO & & $2 \%$ & FINANCIAL & & $3 \%$ & SANTANDER- & & $2 \%$ \\
\hline \multirow{2}{*}{ Total } & $\$$ & 84.786 .885 .339 & \multirow{2}{*}{ Total } & $\$$ & 84.440 .608 .915 & \multirow{2}{*}{ Total } & & 65.458 .081 .995 & \multirow{2}{*}{ total } & & 56.743 .029 .539 \\
\hline & & $\mathbf{5 5 \%}$ & & & $18 \%$ & & & $54 \%$ & & & $29 \%$ \\
\hline
\end{tabular}

Fuente: Elaboración propia

Como se puede observar, la muestra seleccionada posee una participación significativa en relación al mercado bursátil de su país de origen en la mayoría de los casos; en Colombia y en Perú se alcanza una representatividad de más del $50 \%$ lo cual obedece a la poca cantidad de empresas que cotizan en la bolsa de valores y junto a esto se le suma la gran concentración bursátil de algunas de las empresas como lo es Ecopetrol (Colombia) y Southern Copper Corporation (Perú). Mientras que en Chile se alcanza casi una tercera parte del total del mercado. En el caso de México, la representatividad de la muestra seleccionada alcanza un $18 \%$ del total de la capitalización bursátil de este país, cifra que se hace significativa al considerar la cuantía de su Capital Bursátil en relación con los demás países.

Por otro lado, las empresas seleccionadas se encuentran en su mayoría en el Índice de Sostenibilidad Dow Jones (DJSI), lo que muestra sus buenas prácticas en el desempeño económico, social y ambiental además de unos altos estándares de sostenibilidad y creación de valor a largo plazo.

Tabla 4. Muestra empresas MILA DJSI

\begin{tabular}{|c|c|c|c|c|c|c|c|c|c|c|}
\hline $\begin{array}{l}\text { COMPANY } \\
\text { NAME }\end{array}$ & $\begin{array}{l}\text { Banco de } \\
\text { Chile }\end{array}$ & $\begin{array}{l}\text { Banco } \\
\text { Santander } \\
\text { Chile } \\
\end{array}$ & $\begin{array}{l}\text { ENDESA (Empresa } \\
\text { Nacional de } \\
\text { Electricidad SA) }\end{array}$ & $\begin{array}{l}\text { Empresas } \\
\text { COPEC SA }\end{array}$ & Enersis SA & $\begin{array}{l}\text { SACI } \\
\text { Falabella }\end{array}$ & $\begin{array}{l}\text { Banco de } \\
\text { Bogota SA }\end{array}$ & $\begin{array}{l}\text { Bancolombia } \\
\text { SA }\end{array}$ & $\begin{array}{l}\text { E Ecopetrol } \\
\text { SA }\end{array}$ & $\begin{array}{l}\text { Grupo } \\
\text { Argos S.A. }\end{array}$ \\
\hline COUNTRY & Chile & Chile & Chile & Chile & Chile & Chile & Colombia & Colombia & Colombia & Colombia \\
\hline $\begin{array}{l}\text { GICS INDUSTRY } \\
\text { GROUP }\end{array}$ & Banks & Banks & Utilities & Energy & Utilities & Retailing & Banks & Banks & Energy & Materials \\
\hline DJSI WORLD & NO & SI & SI & SI & $\mathrm{SI}$ & $\mathrm{SI}$ & SI & SI & $\mathrm{SI}$ & SI \\
\hline $\begin{array}{c}\text { DJSI EMERGING } \\
\text { MARKETS }\end{array}$ & SI & SI & SI & SI & SI & SI & SI & SI & SI & SI \\
\hline $\begin{array}{l}\text { COMPANY } \\
\text { NAME }\end{array}$ & \begin{tabular}{|l|} 
Grupo Aval \\
Acciones y \\
Valores \\
\end{tabular} & $\begin{array}{l}\text { Grupo de } \\
\text { Inversiones } \\
\text { Suramericana }\end{array}$ & $\begin{array}{l}\text { Credicorp } \\
\text { Limited }\end{array}$ & $\begin{array}{l}\text { Southern } \\
\text { Copper } \\
\text { Corp }\end{array}$ & $\begin{array}{l}\text { America } \\
\text { Movil SAB } \\
\text { de CVL } \\
\end{array}$ & $\begin{array}{l}\text { Cemex SA } \\
\text { CPO }\end{array}$ & $\begin{array}{l}\text { Fomento } \\
\text { Economico } \\
\text { Mexico } \\
\end{array}$ & $\begin{array}{l}\text { Grupo } \\
\text { Financiero } \\
\text { Banorte O } \\
\end{array}$ & $\begin{array}{l}\text { Grupo } \\
\text { Mexico SAB } \\
\text { de CV B } \\
\end{array}$ & $\begin{array}{l}\text { Grupo } \\
\text { Televisa } \\
\text { SAB CPO } \\
\end{array}$ \\
\hline COUNTRY & Colombia & Colombia & Peru & Peru & Mexico & Mexico & Mexico & Mexico & Mexico & Mexico \\
\hline $\begin{array}{l}\text { GICS INDUSTRY } \\
\text { GROUP }\end{array}$ & Banks & $\begin{array}{c}\text { Diversified } \\
\text { Financials }\end{array}$ & Banks & Materials & $\begin{array}{l}\text { Telecommu } \\
\text { nication }\end{array}$ & Materials & $\begin{array}{c}\text { Food, } \\
\text { Beverage \& }\end{array}$ & Banks & Materials & Media \\
\hline DJSI WORLD & SI & SI & SI & SI & SI & $\mathrm{SI}$ & SI & SI & SI & SI \\
\hline $\begin{array}{c}\text { DJSI EMERGING } \\
\text { MARKEIS }\end{array}$ & SI & SI & SI & SI & SI & SI & $\mathrm{SI}$ & $\mathrm{SI}$ & SI & SI \\
\hline
\end{tabular}

Fuente: Elaboración propia 
Soto, M.; Giraldo, J.; Mejía, J. Características de la información contenida en los reportes integrados...

En última instancia para el manejo y recopilación de información, se ha estructurado una matriz en donde están planteadas las variables que serán objeto de análisis. Estas han sido definidas tomando como base la guía de aplicación GRI (Global Reporting Initiative) en su versión G4, conceptos de algunos autores y otros fundamentos que, a criterio del grupo investigador, tras el rastreo bibliográfico realizado, se ajustan y son pertinentes en la presentación de información integrada. Cada elemento cuenta con un grupo de indicadores que se convierten en el soporte del comportamiento mostrado por la variable y permite un análisis y una conclusión posterior.

A continuación, se relacionan las variables seleccionadas:

Tabla 5. Indicadores de la Matriz

\begin{tabular}{|c|c|}
\hline Vble & Nociones de referencia \\
\hline 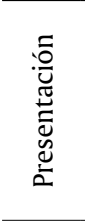 & $\begin{array}{l}\text { "El beneficio principal de la presentación integrada de reportes es que le permite a la compañía } \\
\text { entender de mejor manera, administrar y reportar sobre las múltiples dimensiones del valor." } \\
\text { (Novo Nordisk, } 2011 \text { citado en Main y Henspenheide 2012). En esta variable se toman indicadores } \\
\text { que denoten uniformidad y comparabilidad para poner en evidencia las tendencias implícitas en } \\
\text { la preparación de los informes con el fin de brindar un panorama general de las prácticas con las } \\
\text { que estos se desarrollan. }\end{array}$ \\
\hline & $\begin{array}{l}\text { En relación con la variable económica, uno de los ítems que sobresalen en la Guía G4 del GRI es } \\
\text { el valor económico generado que se ve representado por medio de los ingresos, para reflejar la } \\
\text { capacidad en la distribución que posee la compañía. En adición a esto se consideran elementos } \\
\text { de análisis financiero que permiten "evaluar el desempeño de una empresa en el contexto de sus } \\
\text { metas y estrategias declaradas" (Palepu, Healy y Bernard, } 2002 \text { P. 9-1) y le dan al inversionista un } \\
\text { panorama que resulta influyente en la toma de sus decisiones. }\end{array}$ \\
\hline 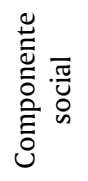 & $\begin{array}{l}\text { La información con respecto al desempeño social de la compañía "está relacionada con la } \\
\text { repercusión de las actividades de una organización en los sistemas sociales en los que opera" } \\
\text { (Global Reporting Initiative, 2013). Ninguna organización es ajena a las comunidades en las que } \\
\text { realiza sus operaciones, por lo tanto se hace necesario que se presente información que permita } \\
\text { medir el impacto positivo o negativo que tienen las empresas en dicho entorno. }\end{array}$ \\
\hline 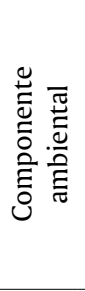 & $\begin{array}{l}\text { En la década de los 90`s las preocupaciones medioambientales como "el calentamiento global, } \\
\text { el deterioro de la capa de ozono, los desequilibrios climáticos globales, la extinción de especies } \\
\text { animales y vegetales (...) entre muchos otros factores" (Gómez, 2009, p. 62) incentivaron la } \\
\text { existencia de información de este tipo. En la actualidad las empresas buscan estar en índices } \\
\text { relacionados con prácticas amigables con el ambiente, según Moneva y Ortas 2009, "siendo los } \\
\text { más destacados los pertenecientes a la familia del Dow Jones Sustainability Group y el FTSE4GOOD } \\
\text { indexes". (p.143) Dentro de GRI G4 es un ítem general realizar un desglose de gastos e inversiones } \\
\text { ambientales, que denoten las acciones para mitigar los efectos de lo ocasionado. }\end{array}$ \\
\hline 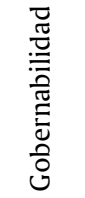 & $\begin{array}{l}\text { Gobierno corporativo representa "toda una estructura dentro de una organización qué muestra la } \\
\text { manera en que ésta es gobernada, vigilada y administrada" (Deloitte, 2015), y es por esto que al } \\
\text { detallar acerca de la cantidad de miembros de junta directiva, el número y el tipo de comités de } \\
\text { apoyo que tenga, además de otros aspectos se genera una comprensión de la capacidad existente } \\
\text { en la toma decisiones estratégicas que influyen en la generación de valor de una organización. }\end{array}$ \\
\hline
\end{tabular}

Fuente: Elaboración propia 


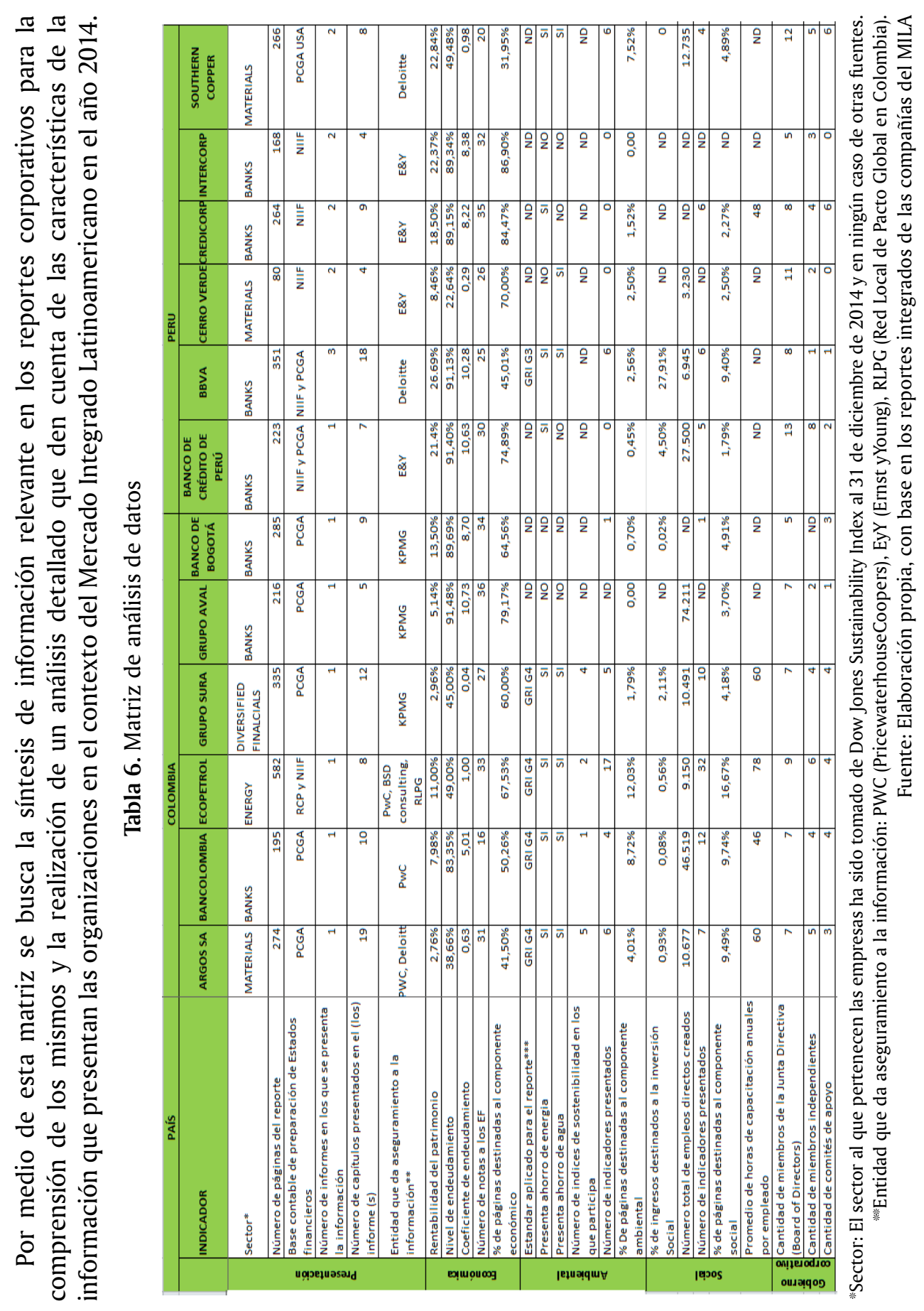


Soto, M.; Giraldo, J.; Mejía, J. Características de la información contenida en los reportes integrados...

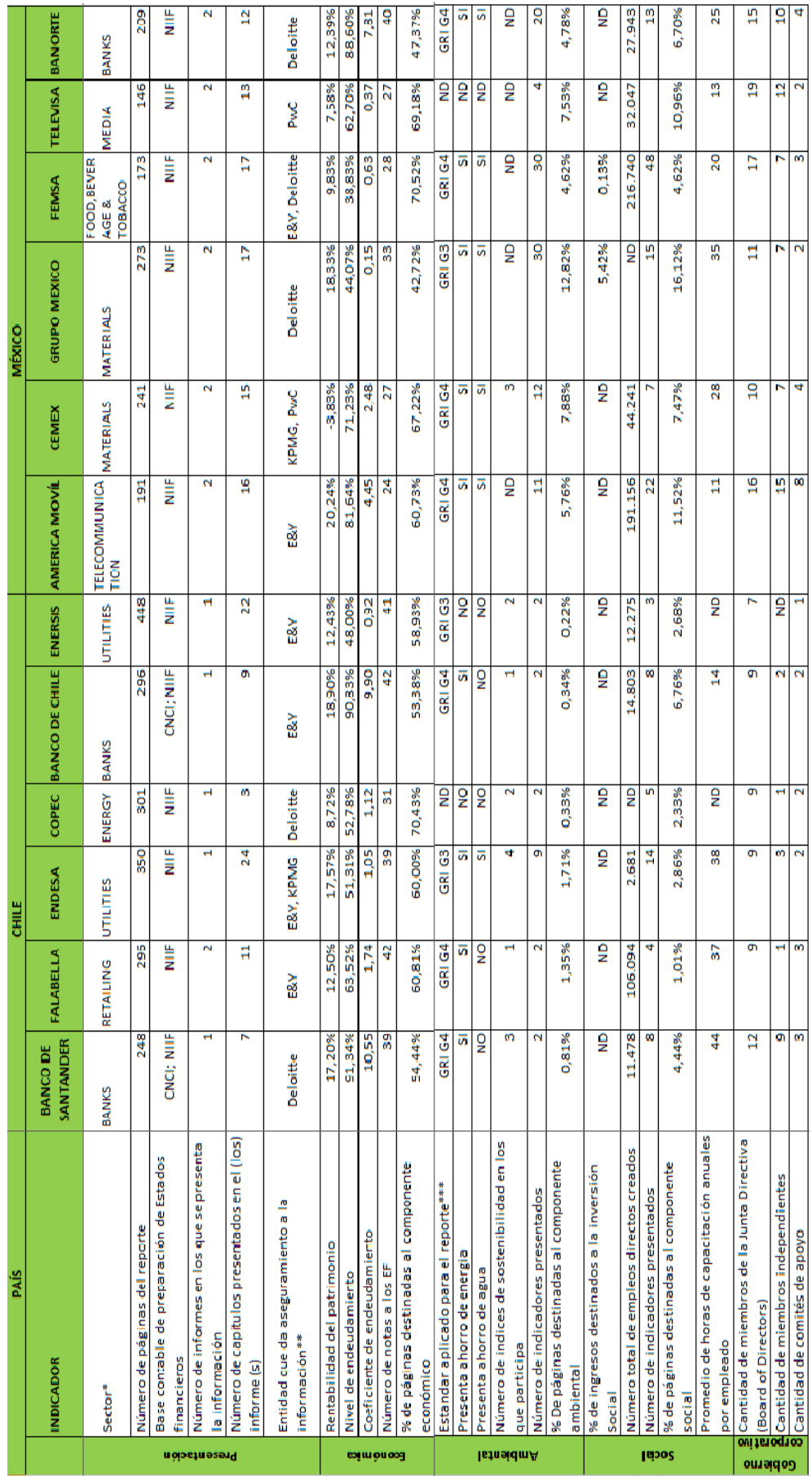




\section{VI.Análisis de resultados: reportes integrados de las empresas del mercado integrado latinoamericano.}

Las empresas desde finales del siglo XX han comenzado una tendencia de revelación de información cada vez más detallada, este suceso ocurre debido a la pérdida de confianza que se tiene en las entidades por parte de los usuarios ocasionado por los fraudes y desfalcos desde los años 80 's, además de la creciente necesidad de mostrar una imagen de la empresa con sentido de responsabilidad social y ambiental.

Esta necesidad se ve materializada en los reportes corporativos que las empresas desarrollan para mostrar los logros y metas alcanzadas, en los cuales se condensa la información de tipo económica, social y ambiental para satisfacer los requerimientos de información de todos los usuarios.

Para realizar el análisis de la información, se estableció una serie de relaciones entre los componentes de la matriz antes definida: estructura del reporte; Componente económico, social, ambiental y gobierno corporativo, que permitieron identificar características y tendencias en la presentación de los reportes integrados del MILA en el año 2014.

Cabe aclarar que la información que se analizó fue extraída de los informes corporativos de las empresas que conforman la muestra, los cuales fueron tomados de su sitio web, con excepción de algunas compañías de Perú en donde, ante la imposibilidad de encontrar información de páginas electrónicas, fue necesario recurrir al portal WEB de la Bolsa de Valores de Lima BVL para recopilar la información. La excepción se hace extensiva a la fuente de la cual se extrajo el sector de la economía al que pertenecen las organizaciones pues como se mencionó anteriormente éste dato fue tomado del DJSI.

\section{VI.1 Estructura del Reporte}

Gráfico 1. Guía aplicada

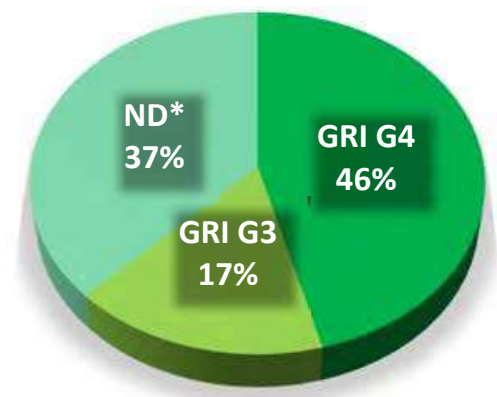

Fuente: Elaboración propia con base en los Informes de las empresas del MILA 
Soto, M.; Giraldo, J.; Mejía, J. Características de la información contenida en los reportes integrados...

Para la realización de los informes, múltiples organismos a nivel mundial han optado por crear unas guías que faciliten la revelación de información para las empresas. Para mencionar bajo que estándar está elaborado un reporte, éste debe haber cumplido con todos los ítems establecidos en la guía acogida. En relación a esto se consideró el estándar aplicado como un punto de partida para conocer su estructura.

Ante las exigencias para preparar información que abarque temas financieros como no financieros el $46 \%$ de las empresas representadas en la muestra del MILA han optado por acoger la guía G4 como base para la elaboración de sus reportes, ésta guía es la última emitida por el GRI, situación que da muestra de la constante actualización y los cambios que están dando las empresas para estar a la vanguardia de los sucesos en los que están involucrados de manera directa. Por su parte se puede observar cómo un $17 \%$ de la muestra seleccionada acoge la guía G3; en estas se presentan una serie de indicadores que tal como se menciona en la página 47 de la guía para la elaboración de informes de sostenibilidad, "ofrecen información sobre el desempeño o los efectos económicos, ambientales y sociales de la organización en referencia a sus Aspectos materiales". (Global Reporting Initiative, 2013), y que dan cuenta de que, si bien no han aplicado la última guía emitida, están comprometidos con los procesos de transformación y de revelación de una información con mayor calidad y de mayor transparencia.

Por su parte un $37 \%$ de empresas no determina explícitamente la base de presentación de su informe, por este hecho no se puede afirmar que haya ausencia de una base de preparación para éste debido a que no se consultaron otras fuentes diferentes al reporte emitido, pero si es una situación que da muestra de aspectos a mejorar y de la necesidad de una mayor concientización para la implementación y adopción de prácticas de revelación acordes a las necesidades y a las tendencias del mercado, para brindar a su vez una información de mayor calidad en el MILA y dar muestra de buenas prácticas en la llamada Alianza del pacifico.

Tabla 8. Cantidad de páginas vs cantidad de reportes

\begin{tabular}{clcc}
\hline País & \multicolumn{1}{c}{ Empresa } & Número de páginas & Q de reportes \\
\hline \multirow{6}{*}{ Colombia } & Grupo Argos & 274 & 1 \\
& Bancolombia & 195 & 1 \\
& Ecopetrol & 582 & 1 \\
& Grupo Sura & 335 & 1 \\
& Grupo Aval & 216 & 1 \\
& Banco de Bogotá & 285 & 1 \\
\hline
\end{tabular}




\begin{tabular}{|c|c|c|c|}
\hline País & Empresa & Número de páginas & $Q$ de reportes \\
\hline \multirow{6}{*}{ Perú } & Banco de Crédito de Perú & 223 & 1 \\
\hline & BBVA & 351 & 3 \\
\hline & Cerro Verde & 80 & 2 \\
\hline & Credicorp & 264 & 2 \\
\hline & Intercorp & 168 & 2 \\
\hline & Southern Copper & 266 & 2 \\
\hline \multirow{6}{*}{ Chile } & Banco de Santander & 248 & 1 \\
\hline & Falabella & 296 & 2 \\
\hline & Endesa & 350 & 1 \\
\hline & Copec & 301 & 1 \\
\hline & Banco de Chile & 296 & 1 \\
\hline & Enersis & 448 & 1 \\
\hline \multirow{6}{*}{ México } & America Movíl & 191 & 2 \\
\hline & Cemex & 241 & 2 \\
\hline & Grupo México & 273 & 2 \\
\hline & Femsa & 173 & 2 \\
\hline & Televisa & 146 & 2 \\
\hline & Banorte & 209 & 2 \\
\hline
\end{tabular}

Fuente: Elaboración propia con base en los informes de las empresas del MILA

En cuanto a las páginas de los reportes estas pueden dar una noción de la cantidad de información que las empresas revelan y la segmentación de la misma para comunicar a sus grupos de interés. Como se puede ver en la tabla anterior, sin importar el número de páginas que tengan los reportes, existe una tendencia que está enmarcada en el país de origen de las empresas, es así como las empresas de Colombia y Chile revelan la información en un reporte consolidado que ayuda a los usuarios a tener toda la información disponible en un solo documento, mientras que en las empresas correspondientes a Perú y México se evidencia como los informes se diversifican en promedio a dos, donde los estados financieros y el informe anual se presentan de manera individual, mostrando en cada uno de estos y de manera detallada la labor realizada.

Se puede mencionar que la extensión de cada reporte está ligada a las prácticas de revelación que tiene cada empresa y a los intereses y prioridades que estas presentan, es así como se explica que una entidad como Ecopetrol de Colombia que tiene la mayor extensión en cantidad de páginas (582 págs.) presenta su información en un reporte consolidado, mientras que la Sociedad Minera Cerro Verde de Perú suma 80 páginas distribuidas en 2 reportes. 
Soto, M.; Giraldo, J.; Mejía, J. Características de la información contenida en los reportes integrados...

Por otro lado, se puede considerar al sector como un factor que incide en la revelación de información de las empresas, según Rodríguez (2004) señala que entre las variables que mayor incidencia tiene en la cantidad de información a revelar se encuentra el sector. Esto se debe a que hay una tendencia a revelar mayor información en aquellos que tienen un impacto directo en la sociedad y en el medio ambiente sea este tanto monetario como afecciones directas en el entorno.

Tabla 9. Páginas del reporte y Sector de las empresas

\begin{tabular}{|c|c|c|c|}
\hline Sector & Empresa & Páginas por Empresa & Prom. de $\mathrm{N}^{\circ}$ de Pág. del Reporte \\
\hline \multirow{10}{*}{ Banks } & Banco de Bogotá & 285 & \multirow{10}{*}{245,5} \\
\hline & Banco de Chile & 296 & \\
\hline & $\begin{array}{l}\text { Banco de Crédito de } \\
\text { Perú }\end{array}$ & 223 & \\
\hline & Banco de Santander & 248 & \\
\hline & Bancolombia & 195 & \\
\hline & Banorte & 209 & \\
\hline & BBVA & 351 & \\
\hline & Credicorp & 264 & \\
\hline & Grupo Aval & 216 & \\
\hline & Intercorp & 168 & \\
\hline $\begin{array}{l}\text { Diversified } \\
\text { finalcials }\end{array}$ & Grupo Sura & 335 & 335 \\
\hline \multirow{2}{*}{ Energy } & Copec & 301 & \multirow{2}{*}{441,5} \\
\hline & Ecopetrol & 582 & \\
\hline $\begin{array}{l}\text { Food,beverage y } \\
\text { tobacco }\end{array}$ & Femsa & 173 & 173 \\
\hline \multirow{5}{*}{ Materials } & Cemex & 241 & \multirow{5}{*}{226,8} \\
\hline & Cerro Verde & 80 & \\
\hline & Grupo Argos & 274 & \\
\hline & Grupo México & 273 & \\
\hline & Southern Copper & 266 & \\
\hline Media & Televisa & 146 & 146 \\
\hline Retailing & Falabella & 296 & 296 \\
\hline Telecommunication & America Móvil & 191 & 191 \\
\hline \multirow{2}{*}{ Utilities } & Endesa & 350 & \multirow{2}{*}{399} \\
\hline & Enersis & 448 & \\
\hline
\end{tabular}

Fuente: Elaboración propia con base en los informes de las empresas del MILA 
De acuerdo al gráfico 2 se puede considerar que generalmente se cumple la afirmación antes mencionada, donde las empresas que se encuentran en los sectores de producción de energía y materiales poseen una buena revelación de información, debido a que se tratan de sectores sensibles. Por otro lado, las empresas que pertenecen al sector financiero poseen menor rango de información a excepción del Grupo sura (diversified finalcials), Banco BBVA (Banks), Endesa (Utilities) y Enersis (Utilities) las cuales presentan una mayor cantidad de páginas reveladas, solo siendo superados por Ecopetrol (Energy).

Además de la forma de presentación contenida en un reporte, el aseguramiento de la calidad de la información reviste una gran importancia en el momento de determinar la confiabilidad de los datos obtenidos, en la tabla 10 se presentan las entidades que aseguran su informe no financiero.

Tabla 10. Aseguramiento de la información

\begin{tabular}{|c|c|c|c|}
\hline País & Empresa & Aseguramiento a los EF & $\begin{array}{c}\text { Aseguramiento de la información } \\
\text { no financiera }\end{array}$ \\
\hline \multirow{6}{*}{ Colombia } & Grupo Argos & Deloitte & Deloitte \\
\hline & Bancolombia & $\mathrm{PwC}$ & Deloitte \\
\hline & Ecopetrol & $\mathrm{PwC}$ & BSD consulting, RLPG en Colombia \\
\hline & Grupo Sura & KPMG & Deloitte \\
\hline & Grupo Aval & KPMG & NO \\
\hline & Banco de Bogotá & KPMG & NO \\
\hline \multirow{6}{*}{ Perú } & Banco de Crédito de Perú & EyY & NO \\
\hline & BBVA & Deloitte & Deloitte \\
\hline & Cerro Verde & EyY & NO \\
\hline & Credicorp & EyY & NO \\
\hline & Intercorp & EyY & NO \\
\hline & Southern Copper & Deloitte & NO \\
\hline \multirow{6}{*}{ Chile } & Banco de Santander & Deloitte & Deloitte \\
\hline & Falabella & EyY & NO \\
\hline & Endesa & EyY & KPMG \\
\hline & Copec & Deloitte & NO \\
\hline & Banco de Chile & EyY & NO \\
\hline & Enersis & EyY & EyY \\
\hline \multirow{6}{*}{ México } & America Móvil & EyY & NO \\
\hline & Cemex & KPMG & $\mathrm{PwC}$ \\
\hline & Grupo México & Deloitte & Deloitte \\
\hline & Femsa & EyY & Deloitte \\
\hline & Televisa & $\mathrm{PwC}$ & NO \\
\hline & Banorte & Deloitte & Deloitte \\
\hline
\end{tabular}

Fuente: Elaboración propia con base en los informes de las empresas del MILA 
Soto, M.; Giraldo, J.; Mejía, J. Características de la información contenida en los reportes integrados...

El aseguramiento de la información en los reportes integrados transmite al usuario consistencia y confiabilidad en los datos presentados, frente a la revisión de los reportes seleccionados para esta investigación, en la tabla 10 se evidencia como la información financiera ha sido auditada y cuenta con el respaldo de entidades pertenecientes al llamado big 4 (PwC, EyY, Deloitte y Touch y KPMG); organizaciones que prestan servicios profesionales con alto grado de evaluación y de reconocimiento a nivel mundial.

La totalidad de los estados financieros de las empresas de la muestra de este trabajo cuentan con un dictamen emitido por alguna de las compañías "Big 4", como se muestra en la tabla 10, aunque todas empresas cuentan con aseguramiento en sus estados financieros, no sucede lo mismo con el aseguramiento de la información no financiera. Esta situación es entendible dado a que el manejo de cuantiosos flujos de capital por parte de las empresas hace que la regulación de cada país exija procedimientos y evaluaciones rigurosas, por otra parte la información de datos no financieros no está asegurada en todos los casos, esto debido a que "hay menos experiencia en la prestación de aseguramiento externo para los usuarios de datos no financieros que la que hay para la auditoría de datos financieros, la cual tiene décadas de desarrollo" (Main y Henspenheide, 2012, p. 135) dejando de manifiesto la idea de que sigue prevaleciendo la información financiera mientras que la información de carácter no financiero pasa a un segundo plano.

VI.2 Relación componente económico y estructura del reporte

El nivel de endeudamiento es uno de los factores que ejerce influencia en la cantidad de información que se presenta, conforme se incrementa la deuda, la demanda de información por parte de los acreedores también aumenta puesto que estos necesitan conocer la capacidad que la compañía posee para cumplir sus obligaciones (Rodríguez, L. Gallego, I. y García I, M. 2010)

Tabla 11. Nivel de endeudamiento vs promedio de páginas por punto porcentual.

\begin{tabular}{lcc}
\hline \multicolumn{1}{c}{ Sector } & Nivel de endeudamiento & Promedio de páginas \\
\hline Banks & $89.6 \%$ & 2.73 \\
Telecommunication & $81.6 \%$ & 2.34 \\
Retailing & $63.5 \%$ & 4.66 \\
Media & $62.7 \%$ & 2.33 \\
Energy & $50.9 \%$ & 8.79 \\
Utilities & $49.7 \%$ & 8.08 \\
Materials & $45.2 \%$ & 5.12 \\
Diversified finalcials & $45.0 \%$ & 7.44 \\
Food,beverage y tobacco & $38.8 \%$ & 4.46 \\
\hline
\end{tabular}


Fuente: Elaboración propia con base en los informes de las empresas del MILA

En el gráfico 4 llama la atención los altos niveles de endeudamiento, esto es debido a que la mayoría de empresas que presentan esta tendencia hacen parte del sector financiero en donde esta estructura es natural. Como lo menciona Rodríguez, Frías y García "varios estudios han encontrado un efecto positivo de la influencia del endeudamiento sobre la cantidad de información revelada de forma voluntaria (...), mientras que otros trabajos no encuentran una relación estadísticamente significativa” (2012, pág. 10). En este trabajo no se evidencia una relación marcada entre estas dos variables pues las compañías que tienen un nivel de endeudamiento más elevado no necesariamente son las que presentan una mayor extensión de páginas en sus reportes, esto debido a diversos factores, a modo de ejemplo las entidades que pertenecen al sector financiero presentan un menor nivel de información ya que sus acreedores están diversificados y el interés principal se centra en datos cuantitativos.

En cuanto a los sectores diferentes al financiero, se presenta una tendencia a revelar información más detallada y se evidencia el interés por mantener unos niveles de propiedad equilibrados en donde el uso de la opción de financiar sus operaciones con recursos de terceros no comprometa la propiedad del negocio ni ponga en riesgo el control del mismo.

Desde la perspectiva de la teoría de las señales se puede considerar a la rentabilidad como un indicador para la cantidad de información a revelar. Según Rodríguez, Gallego y García (2010) esta afirmación se entiende válida entendiendo que la rentabilidad del Patrimonio se encuentra en función de la Utilidad después de impuesto (ROE), en donde una mayor utilidad reflejada en mayores ingresos percibidos por la empresa impulsará a la organización a revelar más información con el fin obtener ventajas competitivas.

Gráfico 2. Páginas del Reporte vs Rentabilidad del patrimonio

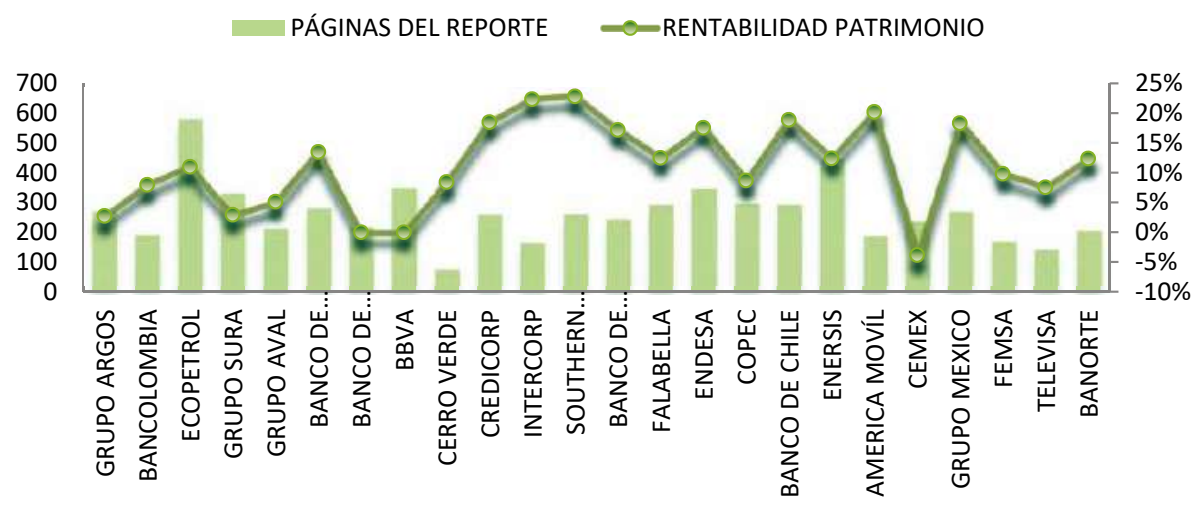

Fuente: Elaboración propia con base en los informes de las empresas del MILA 
Soto, M.; Giraldo, J.; Mejía, J. Características de la información contenida en los reportes integrados...

Respecto a la afirmación de Rodríguez, Gallego y García (2010) antes mencionada, se considera cierta para las empresas de Colombia, Chile y México a excepción del Grupo Cemex (que no tuvo rentabilidad en el 2014), en cuanto a las empresas de Perú no se cumple ya que sus niveles de rentabilidad del patrimonio son muy altos mientras que su cantidad de páginas reveladas es muy baja.

Gráfico 3. Porción de páginas componente económico vs Porción de páginas componentes social y ambiental Vs Sector.

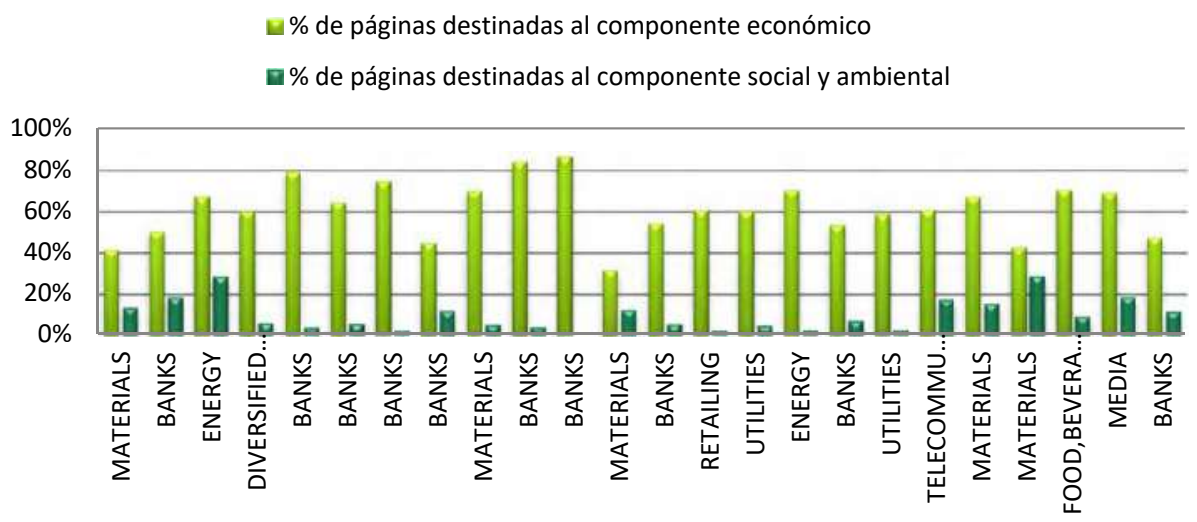

Fuente: Elaboración propia con base en los informes de las empresas del MILA

Como ya se ha mencionado, la revelación de información puede variar según el sector económico en el que opere la empresa, "las empresas situadas en el mismo sector de actividad tendrán prácticas y niveles de revelación de información similares" (Rodríguez, 2004. p. 719) lo cual se da porque las empresas de un mismo sector tienden a tener los mismos costos políticos y los costos de preparación son diferentes entre sectores.

De acuerdo a esto se puede observar que las empresas que revelan una mayor cantidad de información de índole económica y financiera son aquellas que pertenecen al sector financiero (Banks, Utilities, Diversified financials) debido al interés de los acreedores por conocer la capacidad de generar flujos económicos por parte de dichas entidades. Por otro lado, las empresas que se destacan por revelar mayor cantidad de páginas del componente social y ambiental son Grupo Argos, Ecopetrol, Bancolombia, América móvil, Grupo México y Televisa las cuales pertenecen a sectores diferentes al financiero, a excepción de Bancolombia, confirmando que los que tienden a revelar mayor información de tipo económica son aquellas entidades del sector financiero y las que más revelan información de tipo social y ambiental son las que se encuentran en sectores que tienen una incidencia directa en la sociedad y el medio ambiente. Cabe aclarar que, para el cálculo del porcentaje de páginas 
destinadas al componente económico, se tuvo en cuenta, tanto la parte económica como la parte financiera.

Se considera que el porcentaje del componente económico es muy alto respecto a los otros dos componentes, pero como menciona Castillas y Rosselló (2013).

La información sobre datos no financieros se presenta en informes separados o se da una breve descripción de estos en el informe anual, dichos informes suelen ser de Responsabilidad Social Corporativa y/o sostenibilidad, esta situación evita que se tenga una imagen más completa de los riesgos y oportunidades a los que se enfrenta una compañía. (p. 73)

Este planteamiento contribuye con el entendimiento del bajo porcentaje de páginas atribuido a los demás componentes respecto al componente económico.

Gráfico 4. Notas Vs Componente Económico

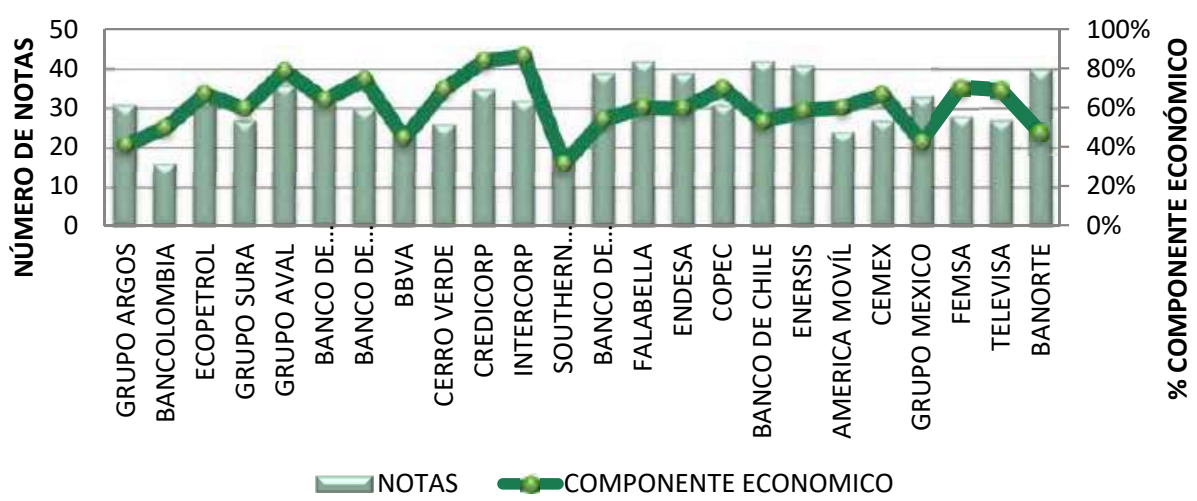

Fuente: Elaboración propia con base en los informes de las empresas del MILA

Por otra parte, las notas a los estados financieros son un factor clave en la revelación de información, pues en estas se brinda una visión más detallada de los negocios que han llevado a cabo las compañías, como se ve en el gráfico 4, en la mayoría de empresas del MILA existe una relación directa entre el número de notas presentadas y las páginas destinadas al componente económico, ya que se privilegia la información de carácter económico y financiero y se brinda un mayor detalle de la misma. 
Soto, M.; Giraldo, J.; Mejía, J. Características de la información contenida en los reportes integrados...

\section{VI.3 Componente ambiental y social}

Gráfico 5. Porcentaje de páginas del componente social vs Porcentaje de páginas del componente ambiental.

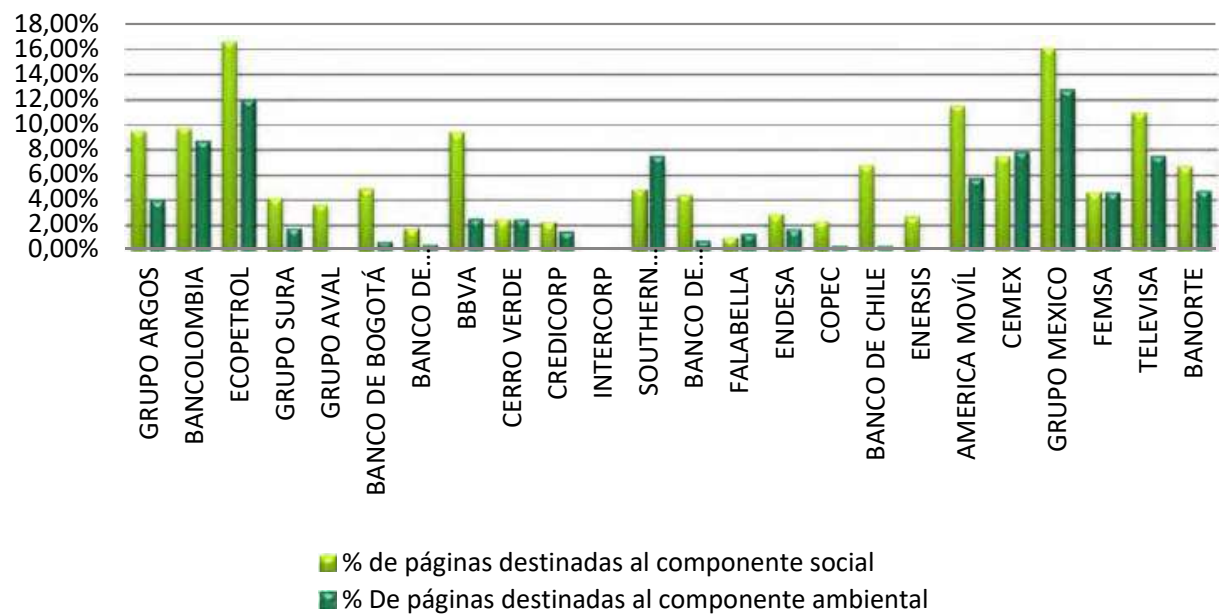

Fuente: Elaboración propia con base en los informes de las empresas del MILA

La revelación de información ambiental y social se convierte en un reto para las empresas, ya que como se mencionó anteriormente, se privilegia la información de tipo financiero y económico. A pesar de esto, se puede considerar que en gran parte las empresas revelan mayor información de carácter social que ambiental a excepción de la empresa Southern Copper de Perú en donde el porcentaje de las páginas destinadas al componente ambiental es mayor. Esto, en relación con el gráfico 5 se puede considerar una tendencia en donde las empresas tienden a revelar mayor información de tipo económica seguida por la información social y finalmente la información ambiental. Esta situación da muestra que el interés general sigue estando enfocado a los resultados financieros-patrimonialistas. 
Gráfico 6. Indicadores Presentados vs Porcentaje de Páginas del Componente Ambiental

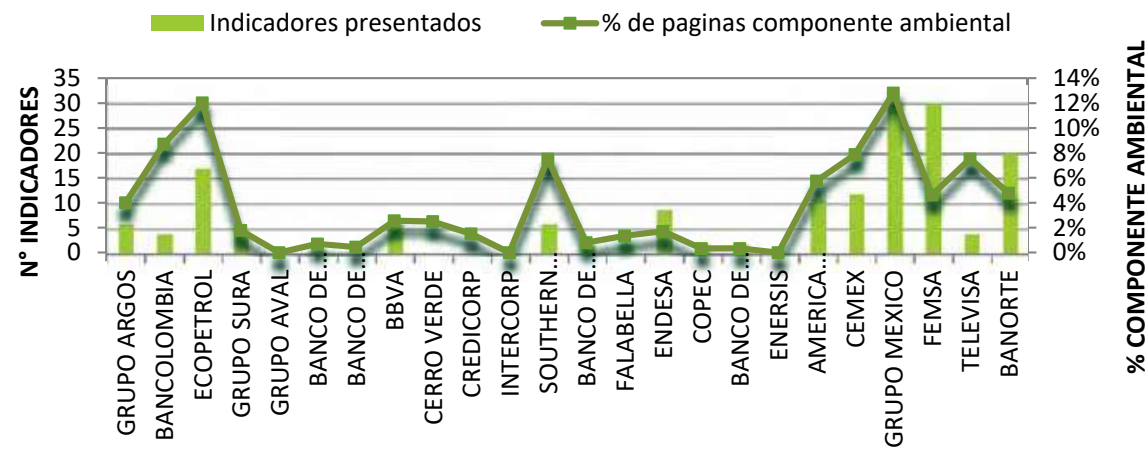

Fuente: Elaboración propia con base en los informes de las empresas del MILA

El número de indicadores que presentan las empresas es una señal de la cantidad de información que quiere revelar la compañía, estos indicadores se cuantificaron con base en el índice de indicadores presentados en los reportes.

En la gráfica 6 se observa una tendencia en la cual mientras más indicadores presenta mayor es el porcentaje de páginas que se destinan al componente analizado. Como se había afirmado anteriormente, las empresas con mayor nivel de indicadores revelados pertenecen a los sectores de Materiales, producción de energía, media y telecomunicaciones, esto por el nivel de influencia que tienen estas compañías en el medio ambiente.

Además del componente ambiental, las organizaciones también se enfrentan a la revelación de información social y uno de los retos más comunes de los directivos de las empresas es el de mejorar la productividad de sus empleados y una de las formas de hacerlo es por medio de la educación ya que "existe una relación directa entre mejoras en educación y mejoras en productividad" (Gómez. 2008). Invertir en la educación de los empleados o capacitarlos en las actividades diarias que llevan a cabo dentro y fuera de la organización no solo mejoran su productividad y la de la compañía, sino que también permite tomar una ventaja competitiva en el mercado; lo que se traduce en mejores resultados y una generación de valor.

Así mismo la cantidad de empleos creados junto al tiempo invertido en capacitación permiten conocer la responsabilidad que se tiene con la sociedad puesto que se reducen los niveles de desempleo y se aumenta la calidad de vida de las personas.

En la siguiente tabla se puede observar como en el MILA para el año 2014, las compañías que tienen un mayor promedio de horas de capacitación por empleado son Ecopetrol, Argos, Bancolombia, Grupo Sura, Credicorp, Banco de Santander y Falabella. Se puede evidenciar que las empresas del sector 
Soto, M.; Giraldo, J.; Mejía, J. Características de la información contenida en los reportes integrados...

tipo industrial (Materials, Energy) son las que mayor tiempo dedican a la capacitación de sus empleados, esto debido la necesidad de tener personal capaz para desenvolverse en las diferentes áreas con eficiencia. Seguidamente se encuentra el sector financiero esto debido al alto riesgo que se maneja en este sector.

Tabla 12. Número de empleados vs Promedio de capacitación por horas

\begin{tabular}{|c|c|c|c|}
\hline País & Empresa & Número de empleados & Promedio de horas de capacitación \\
\hline \multirow{6}{*}{$\frac{\frac{\pi}{0}}{\frac{0}{0}}$} & Grupo Argos & 10.677 & 60,0 \\
\hline & Bancolombia & 46.519 & 46,0 \\
\hline & Ecopetrol & 9.15 & 77,9 \\
\hline & Grupo Sura & 10.491 & 59,9 \\
\hline & Grupo Aval & 74.211 & ND \\
\hline & Banco de Bogotá & ND & ND \\
\hline \multirow{6}{*}{ ב } & Banco de Crédito de Perú & 27.5 & ND \\
\hline & BBVA & 6.945 & ND \\
\hline & Cerro Verde & 3.23 & ND \\
\hline & Credicorp & $\mathrm{ND}$ & 48,0 \\
\hline & Intercorp & ND & ND \\
\hline & Southern Copper & 12.735 & ND \\
\hline \multirow{6}{*}{ 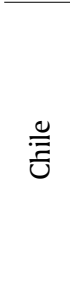 } & Banco de Santader & 11.478 & 44,3 \\
\hline & Falabella & 106.094 & 36,6 \\
\hline & Endesa & 2.681 & 38,0 \\
\hline & Copec & ND & ND \\
\hline & Banco de Chile & 14.803 & 14,3 \\
\hline & Enersis & 12.275 & ND \\
\hline \multirow{6}{*}{$\frac{\stackrel{\theta}{x}}{\stackrel{0}{\Sigma}}$} & America Móvil & 191.156 & 10,8 \\
\hline & Cemex & 44.241 & 28,0 \\
\hline & Grupo México & ND & 34,7 \\
\hline & Femsa & 216.74 & 19,9 \\
\hline & Televisa & 32.047 & 12,8 \\
\hline & Banorte & 27.943 & 25,0 \\
\hline
\end{tabular}

Fuente: Elaboración propia con base en los informes de las empresas del MILA

\section{VI.4 Gobierno Corporativo}

Como se ha mencionado, mantener unas buenas prácticas corporativas permite crear valor en el tiempo, entre las buenas prácticas de cada país se establece que las decisiones y acuerdos que se tengan por la junta directiva 
de cada empresa debe ser realizada por los miembros de la junta de los cuales es importante tener un porcentaje independiente para que las decisiones sean impartidas sin intereses particulares.

Dependiendo de cada país el número de miembros independientes puede variar tal y como se muestra a continuación:

Tabla 13. Porcentaje de miembros independientes de la junta directiva

\begin{tabular}{|c|c|c|c|c|c|c|}
\hline País & Empresa & $\begin{array}{l}\text { Miembros } \\
\text { junta }\end{array}$ & $\begin{array}{c}\text { Indepen. } \\
\text { junta }\end{array}$ & $\begin{array}{c}\% \\
\text { indepen. }\end{array}$ & $\begin{array}{c}\% \text { miembros indep. } \\
\text { Exigidos }\end{array}$ & Referente \\
\hline \multirow{5}{*}{$\frac{\frac{\pi}{0}}{\frac{0}{0}}$} & Grupo Argos & 7 & 5 & $71 \%$ & \multirow{5}{*}{$25 \%$} & \multirow{5}{*}{ Ley 964 de 2005} \\
\hline & Bancolombia & 7 & 4 & $57 \%$ & & \\
\hline & Ecopetrol & 9 & 6 & $67 \%$ & & \\
\hline & Grupo Sura & 7 & 4 & $57 \%$ & & \\
\hline & Grupo Aval & 7 & 2 & $29 \%$ & & \\
\hline \multirow{4}{*}{ 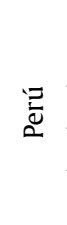 } & $\begin{array}{l}\text { Banco de } \\
\text { Crédito de Perú }\end{array}$ & 13 & 8 & $62 \%$ & \multirow{4}{*}{$33 \%$} & \multirow{4}{*}{$\begin{array}{l}\text { Código de buen } \\
\text { gobierno corporativo } \\
\text { para las empresas } \\
\text { peruanas. Principio } 19 .\end{array}$} \\
\hline & Credicorp & 8 & 4 & $50 \%$ & & \\
\hline & Intercorp & 5 & 3 & $60 \%$ & & \\
\hline & Southern Copper & 12 & 5 & $42 \%$ & & \\
\hline \multirow{5}{*}{ 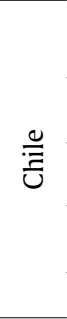 } & $\begin{array}{l}\text { Banco de } \\
\text { Santander }\end{array}$ & 12 & 9 & $75 \%$ & \multirow{5}{*}{$\begin{array}{l}\text { Sugiere que al } \\
\text { menos } 2 \text { de los } 7 \\
\text { miembros }(28 \%) \text { del } \\
\text { directorio deberían } \\
\text { pertenecer } \\
\text { a miembros } \\
\text { independientes. No } \\
\text { es obligatorio. }\end{array}$} & \multirow{5}{*}{$\begin{array}{l}\text { Superintendencia de } \\
\text { valores y seguros de } \\
\text { chile en su informe. "el } \\
\text { reto de modernizar el } \\
\text { mercado bursátil: cinco } \\
\text { principios" }\end{array}$} \\
\hline & Falabella & 9 & 1 & $11 \%$ & & \\
\hline & Copec & 9 & 1 & $11 \%$ & & \\
\hline & Banco de Chile & 9 & 2 & $22 \%$ & & \\
\hline & Endesa & 9 & 3 & $33 \%$ & & \\
\hline \multirow{6}{*}{$\frac{\substack{e \\
x}}{\sum}$} & America Móvil & 16 & 15 & $94 \%$ & \multirow{6}{*}{$25 \%$} & \multirow{6}{*}{$\begin{array}{l}\text { Ley de mercado de } \\
\text { valores del año } 2006 \text {, } \\
\text { articulo } 24 \text {. }\end{array}$} \\
\hline & Cemex & 10 & 7 & $70 \%$ & & \\
\hline & Grupo México & 11 & 7 & $64 \%$ & & \\
\hline & Femsa & 17 & 7 & $41 \%$ & & \\
\hline & Televisa & 19 & 12 & $63 \%$ & & \\
\hline & Banorte & 15 & 10 & $67 \%$ & & \\
\hline
\end{tabular}

Fuente: Elaboración propia con base en los informes de las empresas del MILA

En la tabla se puede observar como las empresas del MILA en su mayoría dan cumplimiento a las buenas prácticas de gobierno corporativo y a la legislación comercial de su respectivo país. Cabe resaltar que para elaboración de esta tabla se han excluido algunas compañías, las cuales no presentaban información clara acerca de los miembros independientes en sus reportes. 
Soto, M.; Giraldo, J.; Mejía, J. Características de la información contenida en los reportes integrados...

Aunque la gran parte de las posturas existentes acerca de los miembros independientes es favorable, también existen autores que no ven en esta figura un acontecimiento relevante pues Gutiérrez y Sáez sostienen que los miembros independientes "carecen de un mandato claro de supervisión, que disponen de herramientas de control muy limitadas, que hay dificultades importantes en la definición de su perfil y en su proceso de selección, y que se les da pocos incentivos" (2012, P. 8), poniendo en duda la efectividad de esta figura en las organizaciones.

Con las relaciones antes establecidas se han generado una serie de hallazgos que generan argumentos para realizar consideraciones finales acerca de las características de los reportes integrados en el MILA para el año 2014 y que serán presentados en el siguiente capítulo.

\section{Consideraciones finales}

El MILA es uno de los acuerdos que ha sobresalido dentro de la Alianza del Pacifico, este mercado ha venido en desarrollo en los últimos tiempos y es por esto que se hace importante conocer las características que presenta la información que este revela, pues como se mencionó a lo largo del trabajo, una buena práctica de revelación en las empresas da muestra de confiabilidad y de transparencia que finalmente consolida la generación de valor agregado y se convierte en parte de ventaja competitiva en el mercado (Correa-García et al., 2016).

La presentación de información no financiera en las empresas del MILA estudiadas, más del $50 \%$ de las empresas adoptan la guía del GRI, ya sea la versión G3 o la versión G4 para la elaboración de sus informes, cabe resaltar que la versión G.4 fue la última versión emitida por el GRI, por lo cual es entendible que aún tenga bajo nivel de implementación. Más allá de lo reciente que sea la guía aplicada, la implementación de estas da un indicio de las buenas prácticas que están adoptando las empresas para mejorar su revelación. El estudio realizado también permite concluir que aún hacen falta esfuerzos para que esta implementación obtenga un mayor alcance, especialmente en las empresas pertenecientes a Perú, en donde las organizaciones analizadas en este trabajo generalmente no determinan explícitamente en sus reportes la información acerca de este ítem en su reporte corporativo.

Se determinó que el aseguramiento de la calidad en la información es un factor que incide en la confiabilidad de los datos obtenidos y en este sentido el respaldo de organizaciones con alta trayectoria en el ámbito profesional reviste una gran importancia ya que es una garantía de veracidad y consistencia. En la región es un tema todavía emergente.

El componente económico en las empresas del MILA representa una mayor proporción comparación con los demás componentes, poniendo de manifiesto 
que aunque se realicen esfuerzos para dar una información más global e integral, abordando temas sociales y ambientales, el componente económico continua sobresaliendo y siendo el principal afluente de información, pues el enfoque hacia los stakeholders es tal que reviste una mayor importancia, ya que esta información es base para que estos tomen las decisiones que requieran. Se deja abierta la incógnita de la conciencia con la que las empresas adoptan los temas de revelación de información de índole ambiental y social, para que futuras investigaciones aborden este tema y logren generar conclusiones que aporten una visión crítica e interpretativa acerca de esta temática.

Aunque el tema de la revelación de información social y ambiental ha venido tomando importancia a nivel empresarial, para el año 2014 en el MILA se observa que el tratamiento que se le da a estos reportes sigue siendo limitado. A pesar de esto las empresas le dan más importancia a la información de tipo social. La cantidad de información que se revela depende del sector al que pertenecen.

En última instancia con respecto al gobierno corporativo se concluye que las empresas tienen claro que el éxito de una buena gestión y de una toma de decisiones acertada está en la elección de miembros que conforme un equipo de gobierno corporativo, además de esto los países ya sea por medio de legislación, de códigos de buen gobierno o de recomendaciones a sus empresas creen que la inclusión de miembros independientes es una buena estrategia para mejorar la información revelada. Generalmente es bien visto que una administración cuente entre su directorio con miembros o consejeros independientes ya que esto da un indicio de fiabilidad en la información, además de ser un indicador de calidad de gobierno corporativo.

Finalmente y tras la consideración de las relaciones que fueron objeto de análisis en este artículo se concluyó de manera general que los reportes emitidos por las empresas del MILA presentan características que satisfacen de manera general los estándares establecidos en las guías emitidas para la presentación y preparación de los mismos, aunque cabe resaltar que aún hay aspectos a fortalecer y acciones a mejorar para realizar la revelación de información, en especial en las empresas originarias de Perú en donde se identificó el mayor número de falencias en cuanto a la presentación de información.

En la presente investigación se logró la caracterización de la información que presenta un segmento de empresas pertenecientes a Colombia, Chile, México y Perú, naciones que a su vez pertenecen a la Alianza del Pacifico que es un acuerdo sobresaliente entre regiones y altamente reconocido en el ámbito global.

Este es un trabajo de caracterización en donde se abordó la información de contenidos específicos que no abarcan la totalidad de los temas referentes 
Soto, M.; Giraldo, J.; Mejía, J. Características de la información contenida en los reportes integrados...

al área de los reportes corporativos y de la revelación de las empresas, por lo que abre las puertas a trabajos no solo en la líneas crítica e interpretativa, sino también de corte positiva donde se puedan demostrar mediante el uso de modelos econométricos las relaciones que a priori fueron esbozadas en este trabajo.

Los trabajos relacionados con la revelación de información, los impactos al medio ambiente, la gerencia basada en el valor, los reportes de sostenibilidad, reportes integrados y en general de todos aquellos temas que actúan como una variable de decisión por parte de los agentes de interés con respecto a una organización se han convertido en un tema de actualidad y han venido en aumento durante los últimos tiempos, en dónde las dinámicas del mercado exigen información abordada desde nuevas perspectivas (financieras y no financieras). Este trabajo puede servir como base para nuevas investigaciones y para nuevos proyectos que quieran ampliar la visión en cuanto a estas temáticas para generar nuevas conclusiones y aportes que ayuden a mejorar el conocimiento actual relacionado con la presentación y revelación de información de no financiera, de sostenibilidad, integrada y el impacto que esta puede generar en las decisiones de los agentes de interés.

\section{Referencias bibliográficas}

Alianza del Pacífico. (28 de abril de 2011). Cumbre de Lima: para la integración profunda. Declaración presidencial sobre la Alianza del Pacífico. Recuperado de http:// alianzapacifico.net/documentos/

Almeida, M. Marimon, F. Llach, J. (2015). Difusión de las memorias de sostenibilidad en Latinoamérica: análisis territorial y sectorial. Estudios gerenciales.31. 139149. Extraído el 22 de noviembre de 2015. http://www.redalyc.org/articulo. oa? id $=21237092001$

Arango P. y Upegui V. (2012). El Impacto En La Bolsa De Valores De Colombia Del Mercado Integrado Latinoamericano Y De La Calificación De Grado De Inversión. Trabajo de Grado para optar al Título de Ingenieros Administradores, Facultad de Ingeniería, Escuela de Ingeniería de Antioquia, Envigado, Colombia.

Archel, P. y Lizarraga, F (2001). Algunos Determinantes De La Información Medioambiental Divulgada Por las Empresas Españolas Cotizadas. [Versión electrónica] Contabilidad Universidad de Navarra, 7(4), 129-153.

Babío, M. R. Muiño, M. F. y Vidal, R. (2003). La influencia del tamaño y la cotización en la publicación de información voluntaria: Un análisis basado en percepciones de costes y beneficios. [versión electrónica]. Revista de contabilidad, 11, 19-55.

Baiman, S., y Verrecchia, R. E. (1996). The Relation Among Capital Markets, Financial Disclosure, Production Efficiency, and Insider Trading. Journal of Accounting Research, $34(1), 1-22$.

Banco Interamericano de Desarrollo. (S.F). México se incorpora al Mercado Integrado Latinoamericano (MILA). Comercio, Extraído el 09 de octubre, 2015 de http:// 
www.iadb.org/es/temas/comercio/mexico-se-incorpora-al-mercado-integradolatinoamericano-mila,9540.html

Castilla, L. y Rosselló, M. (2013). Avances en España. Hacia el Reporting integrado. Boletín de estudios económicos, Extraído el 13 de diciembre de, 2015 de http://dialnet.unirioja.es/servlet/articulo?codigo $=4227893$

Correa, D., y Hernández, P. (2017). Informes de sostenibilidad y su impacto en la creación de valor financiero en las empresas. Contaduría Universidad de Antioquia, (70), 4361.

Correa-García, J. A., Hernández-Espinal, M. C., Vásquez-Arango, L., y Soto-Restrepo, Y. M. (2016). Reportes integrados y generación de valor en empresas colombianas incluidas en el Índice de Sostenibilidad Dow Jones. Cuadernos de Contabilidad, 17(43), 73108. https://doi.org/10.11144/Javeriana.cc17-43.rigv

Deloitte, (2015). Gobierno corporativo como enlace en la generación de valor. Boletín de gobierno corporativo. Párrafo 1. Extraído el 11 de octubre de 2015 https://www2. deloitte.com/content/dam/Deloitte/mx/Documents/risk/GobiernoCorporativo/1 . Gobierno-Corporativo-enlace-valor.pdf

Dinero. (1998, Julio). ¿Qué es la GVB? . Extraído el 5 de noviembre de 2015, de: http:// www.dinero.com/imprimir/15412

García, L. M. (2015). La cuenta del triple resultado o triple bottom line. Revista de contabilidad y dirección, 20, 65-77.

García, O. L. (2003). El sistema de creación de valor. En Valoración de empresas, gerencia del valor y EVA (pp 1-28). Cali: Prensa Moderna Impresores S.A.

Gil, Laura (2012): Gobierno corporativo vinculado a la divulgación de información previsional: análisis empírico de empresas españolas en un entorno de inestabilidad económica. Extraído el 5 de noviembre de 2015, de: https:/www.uam.es/personal_ pdi/economicas/paalonso/Archivos/gilpascual.pdf

Global Reporting Initiative. (2013). Guía para la elaboración de memorias de sostenibilidad G4. Extraído el 30 de septiembre de 2015. https://www.globalreporting.org/ resourcelibrary/Spanish-G4-Part-One.pdf

Gómez M. (2009). Tensiones, posibilidades y riesgos de la contabilidad medioambiental empresarial. Contaduría Universidad de Antioquia, 54, 55-78.

Gómez R. (2008). Desarrollar destrezas para la competitividad de Colombia. Al tablero. 48. Extraído el día 5 de enero de 2016 de http:/www.mineducacion.gov.co/1621/ article-183961.html

Gutiérrez, M, y Sáez, M, (2012) El mito de los consejeros independientes. InDret, febrero, 1-44.

Hernández Bernal, J. A. y Muñoz Angulo, L. G. (2015). Comercio y evolución de la Alianza del Pacífico. Equidad y Desarrollo, (24), 97-118.

Integrated Reporting - IR. (2011). Hacia la Información Integrada: La comunicación de valor en el Siglo XXI. Traducción AECA, 4.

International Integrated Reporting Council. (2013). El marco Internacional IR. Extraído el 30 de septiembre de 2015. http://integratedreporting.org/wp-content/ uploads/2015/03/13-12-08-THE-INTERNATIONAL-IR-FRAMEWORK-SPANISH-1.pdf 
Soto, M.; Giraldo, J.; Mejía, J. Características de la información contenida en los reportes integrados...

Iñaki Gili, y J. M. Salas. (2005) Memoria de sostenibilidad, aspectos económicos financieros. Barcelona: Ediciones Deusto.

Ionela Corina, Chersan. (2015). Study on practices and tendencies in integrated Reporting. Audit financiar. 13. 91-101. Extraído el 1 de noviembre de 2015, http:// aplicacionesbiblioteca.udea.edu.co:3628/ehost/detail/detail vid =3ysid =53b9afac0142-4204-8dd2-341968b56630\%40sessionmgr4005yhid $=4112 \mathrm{ybdata}=$ Jmxhbmc9Z XMmc2l0ZT1laG9zdC1saXZl

Llorente y Cuenca. (2011). Transacciones en Latinoamérica: La Región Andina irrumpe en el exterior. Bogotá: Autor.

Main, N. Hespenheide, E. (2012). Integrated reporting: The new big picture. [Version electronica]. Deloitte review.10, 123-137.

Marianne, L. J. (2015). The benefits of sustainability and integrated reporting: an investigation of accounting majors perceptions [version electronic]. Journal of legal, ethical and regulatory, 1, 1-20.

Marín, M. del P., Maldonado, S. y Sanmiguel, L. (2012). Análisis empírico de la divulgación de información social en Chile: un estudio en empresas cotizadas [Versión electrónica]. Economía gestión y desarrollo, 13, 121-153.

Mascareñas, J. (1999). Introducción a las Finanzas Corporativas. Extraído el 5 de Noviembre de 2015, de: http://www.ucm.es/info/jmas/mon/01.pdf

Ministerio de Comercio, Industria y Turismo (S.f). 100 preguntas de la Alianza del Pacifico. Acuerdos comerciales y de inversión. Extraído el 26 de enero, 2016 de http://www. mincit.gov.co/tlc/publicaciones.php?id $=7180$

Moneda, J. Llena, F. (1996). Análisis De La Información Sobre Responsabilidad Social En Las Empresas Industriales Que Cotizan En Bolsa [Versión electrónica]. Revista Española de Financiación y Contabilidad, 87(25), 361-401.

Moneva, J. Ortas, E. (2009). Desarrollo sostenible e información corporativa: evolución y situación actual. 139-154. extraído el 25 de septiembre de 2015 de http://dialnet. unirioja.es/servlet/articulo?codigo $=2964677$

Monterio. B. J. (2013). Integrated Reporting and the potential role of XBRL [version electronica]. Strategic finance, 95, 62-65

Palepu, K. Healy, P. Bernard, V. (2002). Análisis y evaluación de negocios mediante estados financieros. (pp 9-1). Thomson learning: editorial.

Rodríguez Pérez, Gonzalo. (2004). Factores explicativos de la revelación voluntaria de información sobre fuentes de ventaja competitiva empresarial [Versión electrónica]. Revista española de financiación y contabilidad. 33. 705-739.

Rodríguez, L. Frías, J. García, R. (2012). El consejo de administración y las memorias de sostenibilidad. Revista de contabilidad - Spanish Accounting Review. 17, 5-16

Rodríguez, L. y Gallego, I. y García, I. M. (2010). Determinantes de la divulgación voluntaria de información estratégica en internet: un estudio de las empresas españolas cotizadas [Versión electrónica]. Revista Europea de Dirección y Economía de la Empresa, 1 (9), 9-26.

WBCSD, W. B. C. for S. D. (2017). Reporting matters: Striking a balance between disclosure and engagement. 